OLIVER, Guillermo. “Algunos problemas de aplicación de reglas de determinación legal de la pena en el Código Penal chileno".

Polít. crim. Vol. 11, No 22 (Diciembre 2016), Art. 13, pp. 766-793.

[http://www.politicacriminal.cl/Vol_11/n_22/Vol11N22A13.pdf]

\title{
Algunos problemas de aplicación de reglas de determinación legal de la pena en el Código Penal chileno
}

\section{Certain problems regarding the application of rules for the legal determination of penalties in the Chilean Penal Code}

\author{
Guillermo Oliver Calderón* \\ Profesor Titular de Derecho Penal y Derecho Procesal Penal, Pontificia Universidad \\ Católica de Valparaíso \\ guillermo.oliver@pucv.cl
}

\section{Resumen}

A pesar de que el Código Penal chileno es muy antiguo, por lo que ha habido mucho tiempo para estudiar y comprender las reglas de su sistema de determinación de penas, presenta todavía varios problemas interpretativos en esta materia. A ello ha contribuido un cierto desdén de la doctrina tradicional por sistematizar cabalmente estos contenidos de la Parte general del Derecho penal, privilegiando el análisis de la teoría del delito, y una consecuente superficialidad de su tratamiento en la jurisprudencia. En este trabajo se examina e intenta solucionar algunos de esos problemas interpretativos, concretamente, en tres de las reglas del sistema de determinación legal de la pena contenidas en el mencionado Código, que quizás sean las que mayores dudas generan: en la relativa a la forma de efectuar los aumentos o disminuciones de pena, en la concerniente a las penas alternativas y en la relativa a las rebajas de pena por intervención delictiva no constitutiva de autoría.

Palabras clave: Determinación de la pena, individualización de la pena, cuantificación de la pena, conmensuración de la pena, medición de la pena, aplicación de la pena.

\begin{abstract}
Although the Chilean Penal Code is very old, so there has been plenty of time to study and understand the rules of its system for determining penalties, it still has several interpretative problems in this area. Certain disdain of the traditional doctrine for fully systematizing these contents of the General part of Criminal law has contributed to this, privileging the analysis of the theory of crime, and a consequent superficiality of its treatment in jurisprudence. This paper examines and attempts to solve some of those interpretative problems, specifically in three of the rules of the system of legal determination of the sentence contained in the mentioned Code, which may be those that generate the most doubts: those related to the way to execute penalty increases or decreases, those concerning

\footnotetext{
* Doctor en Derecho por la Universidad de Barcelona. Dirección postal: Avenida Brasil 2950, Valparaíso, Chile. El autor agradece a Manuel Silva Salse, ayudante de investigación, por sus comentarios y por su colaboración en la búsqueda de jurisprudencia y en el proceso de edición de este trabajo.
} 
OLIVER, Guillermo. "Algunos problemas de aplicación de reglas de determinación legal de la pena en el Código Penal chileno".

alternative sentences and those related to the reductions of punishment for criminal intervention that does not constitute authorship.

Key words: Sentencing, individualization of punishment, quantification of sentence, commensuration penalty, measurement of penalty, application of the penalty.

\section{Introducción}

Aun cuando ya en 1898 Raymond Saleilles cuestionaba la distinción entre individualización legal e individualización judicial de la pena, porque, a su juicio, "no hay individualización legal... [1]a ley no puede prever más que especies, no conoce los individuos... [1] o que se ha tomado como casos de individualización legal son motivos de atenuación o de agravación de pena fundada en la mayor o menor gravedad del delito, por consiguiente, en el grado de responsabilidad... [e]s una falsa individualización"1, lo cierto es que la doctrina suele efectuar una diferenciación, dentro del proceso de cuantificación de la pena, entre reglas de determinación legal de la sanción penal y reglas de individualización judicial de la misma ${ }^{2}$ : aquéllas inciden en el marco penal aplicable a un delito, mientras éstas influyen en la concreción de la sanción dentro del marco penal ya determinado $^{3}$.

Se examinan en este trabajo problemas de aplicación de reglas de determinación legal de la pena en el Código Penal chileno ("CP"). Las disposiciones sobre concursos de delitos forman parte de dichas reglas, porque influyen en la fijación del marco penal aplicable en el juzgamiento de varios delitos ${ }^{4}$. Sin embargo, no se las analiza aquí, porque la temática

\footnotetext{
${ }^{1}$ SALEILLES, Raymond, La individualización de la pena, $2^{\text {a }}$ edición, Trad.: DE HINOJOSA, Juan; Bogotá: Editorial Leyer, 2005, p. 189, quien también alude a la individualización administrativa de la pena. Similar, DE RIVACOBA Y RIVACOBA, Manuel, Función y aplicación de la pena, Buenos Aires: Depalma, 1993, p. 89.

${ }^{2}$ Quizás se deba a la influencia de Saleilles la utilización, por parte de algunos autores, del vocablo determinación en vez del término individualización, para hacer referencia al primer grupo de reglas.

${ }^{3}$ Cfr., entre otros, DEMETRIO CRESPO, Eduardo, Prevención general e individualización judicial de la pena, Salamanca: Ediciones Universidad de Salamanca, 1999, pp. 41-42; CHOCLÁN MONTALVO, José Antonio, Individualización judicial de la pena. Función de la culpabilidad y la prevención en la determinación de la sanción penal, Madrid: Colex, 1997, pp. 107-109; ZUGALDÍA ESPINAR, José Miguel, "La individualización de la pena en el borrador de parte general del Anteproyecto de Código Penal de 1990", Cuadernos de Política Criminal, Vol. 44 (1991), pp. 459-467, p. 460; CHICHIZOLA, Mario I., La individualización de la pena, Buenos Aires: Abeledo-Perrot, 1967, pp. 55-56, 85-87.

${ }^{4}$ En este sentido, MAÑALICH RAFFO, Juan Pablo, "Determinación y ejecución de la pena", Revista de Derecho, Universidad Adolfo Ibáñez, Vol. 2 (2005), pp. 483-529, p. 484. Esta incidencia en el marco penal no debe hacer creer, empero, que exista unanimidad en la doctrina para considerar como lugar sistemático de la teoría de los concursos de delitos el de la teoría de la pena, ya que si bien dicha opinión parece ser mayoritaria -avalada por la ubicación que dicha materia suele tener en las legislaciones penales de los diversos países-, hay quienes la sitúan en el ámbito de la teoría del delito, en tanto que otros la ubican entre la teoría del delito y la teoría de la pena. Cfr. SANZ MORÁN, Ángel José, El concurso de delitos. Aspectos de política legislativa, Valladolid: Universidad de Valladolid, 1986, pp. 20-24; SUÁREZ LÓPEZ, José María, El concurso real de delitos, Madrid: Edersa, 2001, pp. 29-37.
} 
Polít. crim. Vol. 11, No 22 (Diciembre 2016), Art. 13, pp. 766-793.

[http://www.politicacriminal.cl/Vol_11/n_22/Vol11N22A13.pdf]

concursal plantea una serie de problemas propios de la denominada pluralidad delictiva, cuyo examen minucioso obligaría a extender en demasía este trabajo ${ }^{5}$.

Tengo para mí que las disposiciones que regulan los efectos de las circunstancias modificatorias de responsabilidad penal también forman parte de las reglas de determinación legal de la pena, porque inciden en la fijación del marco dentro del cual el juez debe precisar la sanción a imponer, con independencia de que la alteración de dicho marco sea ordenada o sólo permitida por la ley ${ }^{6}$. No obstante, he decidido no examinar tales disposiciones en esta oportunidad, porque para su mejor entendimiento se las debería analizar en un estudio completo sobre circunstancias modificatorias, que incluyera una teoría general de las mismas ${ }^{\top}$, un examen particular de cada una de ellas y un análisis de sus efectos, lo que también excedería con creces los naturales límites de este trabajo.

Tampoco se analizan aquí todas las reglas del Código Penal chileno cuya pertenencia al sistema de determinación legal de la pena no es objeto de discusión, toda vez que la mayoría de ellas es estudiada en los manuales nacionales y existe relativo consenso acerca de su correcta aplicación. En este trabajo se examinan sólo tres de dichas reglas, las cuales tienen en común el hecho de que presentan algunos problemas interpretativos en cuya solución la doctrina y la jurisprudencia aún no han concordado, y otros que ni siquiera han sido materia de análisis. Me refiero a la regla concerniente al modo de efectuar aumentos o disminuciones de pena, a la regla relativa a las penas alternativas y a ciertos aspectos de la regla sobre rebaja de pena por intervención delictiva no constitutiva de autoría, específicamente, en el caso de las faltas.

\footnotetext{
${ }^{5}$ Piénsese, por mencionar sólo un ejemplo, en la dificultad de determinar cuándo se está frente a un hecho y cuándo ante varios. Sobre el tema, puede verse, entre muchos otros, REYES ALVARADO, Yesid, El concurso de delitos, Bogotá: Ediciones Reyes Echandía Abogados, 1990, pp. 9-75; MAÑALICH RAFFO, Juan Pablo, "El concurso de delitos: bases para su reconstrucción en el Derecho penal de Puerto Rico", Revista Jurídica de la Universidad de Puerto Rico, Vol. 74 (2005), pp. 1021-1211; CARRANZA TAGLE, Horacio, Introducción al concurso de delitos. Criterios sobre unidad y pluralidad delictiva, MontevideoBuenos Aíres: B de F, 2011, passim.

${ }^{6}$ Así, MAÑALICH RAFFO, Juan Pablo, “¿Discrecionalidad judicial en la determinación de la pena en caso de concurrencia de circunstancias atenuantes de la responsabilidad penal?", Informes en Derecho. Doctrina Procesal Penal 2009, No 7 (octubre 2010), pp. 41-67, p. 45. Hay quienes, en cambio, las sitúan dentro de las reglas de individualización judicial de la pena, porque su aplicación quedaría entregada a la discrecionalidad judicial. En este sentido, VAN WEEZEL, Alex, "Compensación racional de atenuantes y agravantes en la medición judicial de la pena", Revista Chilena de Derecho, Vol. 24, N 3 (1997), pp. 459-502, pp. 469-471. Sigue este criterio la sentencia de la Corte Suprema, de 15 de septiembre de 2009, dictada en causa rol $\mathrm{N}^{\circ}$ 3909-2009.

${ }^{7}$ Para una teoría general de tales circunstancias, puede verse GONZÁLEZ CUSSAC, José Luis, Teoría general de las circunstancias modificativas de responsabilidad criminal, Valencia: Universidad de Valencia, 1988, passim; ARIAS EIBE, Manuel, Responsabilidad criminal. Circunstancias modificativas y su fundamento en el Código Penal. Una visión desde la doctrina y la jurisprudencia del Tribunal Supremo, Barcelona: Bosch, 2007, passim; RODRÍGUEZ COLLAO, Luis, "Naturaleza y fundamento de las circunstancias modificatorias de la responsabilidad criminal", Revista de Derecho, Pontificia Universidad Católica de Valparaíso, Vol. 36, № 1 (2011), pp. 397-428.
} 
OLIVER, Guillermo. "Algunos problemas de aplicación de reglas de determinación legal de la pena en el Código Penal chileno".

\section{Problemas en la regla relativa a la forma de efectuar aumentos o disminuciones de penas.}

La sanción que se imponga a quien delinca, puede resultar mayor o menor que aquella que la ley señala en forma abstracta para el respectivo tipo penal. La presencia de circunstancias agravantes puede llevar a la aplicación de una pena superior a la contemplada en el tipo, en tanto que la concurrencia de circunstancias atenuantes, así como el hecho de que el delito no alcance la consumación o se lo cometa en calidad distinta a la de autor, puede llevar a imponer una pena inferior a la establecida en forma abstracta en la ley ${ }^{8}$.

Como es sabido, el aumento o la disminución de las sanciones que por estas razones corresponda hacer han de efectuarse, utilizando las denominadas escalas graduales de pena del artículo 59 del Código Penal. Este precepto contempla cinco escalas: la $\mathrm{N}^{\circ} 1$ contiene sólo penas privativas de libertad (presidio, reclusión y prisión); la $\mathrm{N}^{\circ} 2$ y la $\mathrm{N}^{\circ} 3$ incluyen únicamente penas restrictivas de libertad (confinamiento, extrañamiento, relegación y destierro), en tanto que la $\mathrm{N}^{\circ} 4$ y la $\mathrm{N}^{\circ} 5$ prevén exclusivamente penas privativas de otros derechos (inhabilitaciones y suspensiones) ${ }^{9}$. Las penas en cada escala aparecen mencionadas en orden decreciente de gravedad.

Para efectuar los aumentos o disminuciones de pena y determinar cuál es la sanción superior o inferior que corresponde imponer, es necesario situarse en el lugar que la pena señalada en el tipo ocupa en la respectiva escala, y a continuación, subir o bajar el número de grados que corresponda, dentro de dicha escala ${ }^{10}$.

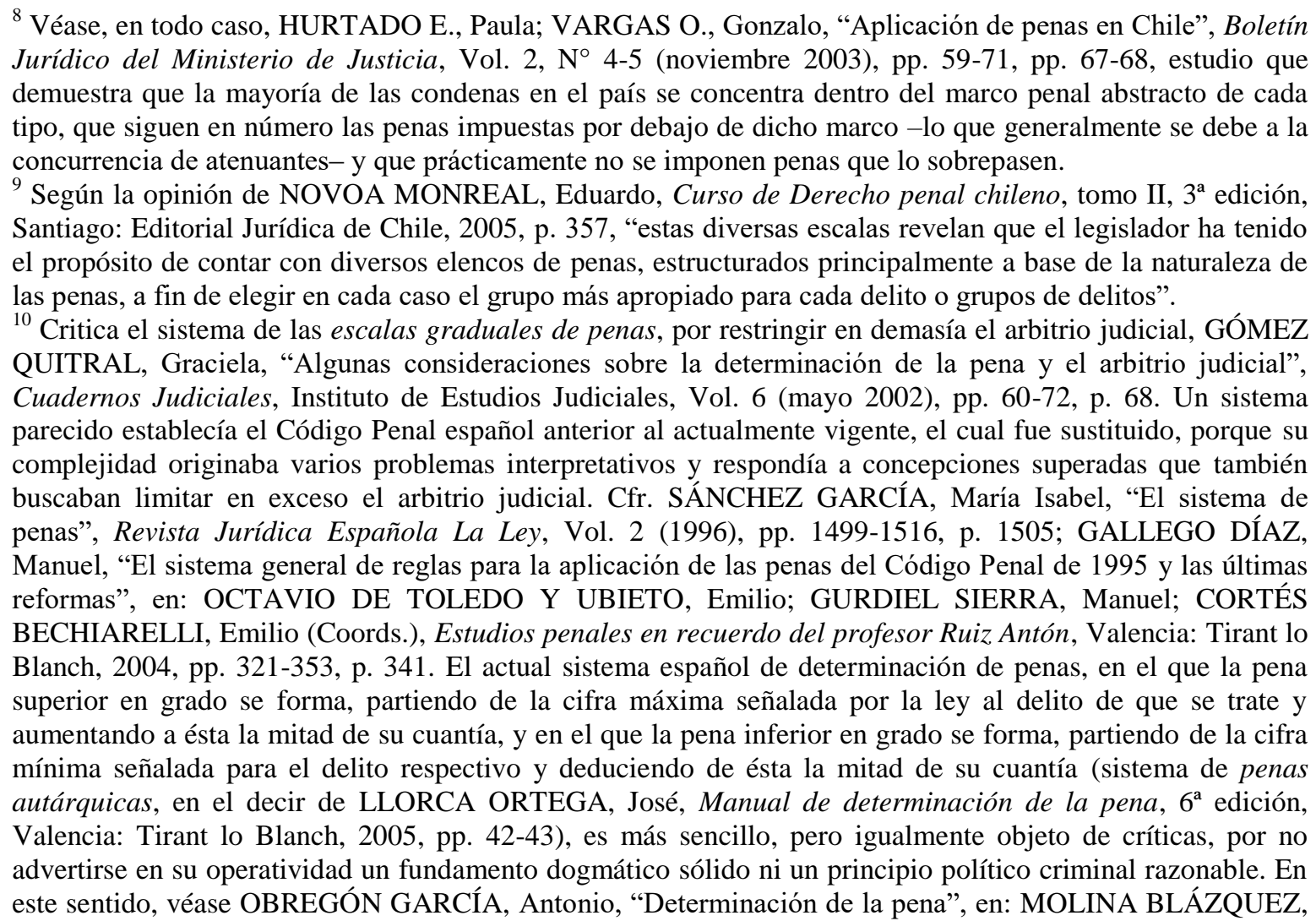


Cuando la pena indicada en el tipo es una sola, la forma de incrementarla o rebajarla es sencilla: después de ubicarla en algún lugar de la escala respectiva, simplemente, se impone la pena superior o inferior en el número de grados que corresponda aumentarla o disminuirla.

Si se trata de una pena compuesta de dos o más grados, también es fácil determinar la manera de disminuirla: debe ubicarse el grado mínimo en algún lugar de la escala respectiva e imponer la pena inferior en el número de grados que corresponda rebajarla. Así se desprende de lo previsto en los artículos 61 regla $2^{\mathrm{a}}$, 66 inciso tercero, 68 inciso tercero, 68 bis y 73 inciso primero del Código Penal, todos los cuales señalan que la rebaja debe hacerse desde el mínimo. En lo que hasta aquí se lleva dicho no existe discusión. La misma solución es propuesta por la doctrina para los casos en que la ley no señala expresamente la forma de disminuir una pena compuesta de varios grados ${ }^{11}$.

Pero la manera de realizar el aumento de esta última clase de penas sí es objeto de debate. Algunos afirman que debe ser hecho a partir del grado máximo, con lo cual el marco penal compuesto por varios grados se convertiría en un solo grado de pena ${ }^{12}$, en tanto que otros sostienen que debe elevarse cada uno de los grados que componen el marco penal, el cual seguiría estando compuesto de varios grados, lo que en la práctica se conoce como aumento "en bloque" . Si bien el debate acerca de la forma de efectuarse el incremento de esta clase de

María Concepción (Coord.), La aplicación de las consecuencias jurídicas del delito, Barcelona: Bosch, 2005, pp. 75-112, pp. 81-82.

${ }^{11}$ Cfr. COUSO SALAS, Jaime, "Comentario previo a los arts. 50 a 69 y 76 a 78 . El sistema de determinación de penas en el Derecho chileno", en: COUSO SALAS, Jaime; HERNÁNDEZ BASUALTO, Héctor (Dirs.), Código Penal Comentado. Parte General. Doctrina y Jurisprudencia, Santiago: Abeledo Perrot Legal Publishing Chile, 2011, pp. 510-524, p. 521.

${ }_{12}$ Así, ORTIZ QUIROGA, Luis; ARÉVALO CUNICH, Javier, Las consecuencias jurídicas del delito, Santiago: Editorial Jurídica de Chile, 2013, p. 292. En igual sentido, implícitamente, PICA URRUTIA, René, Reglas para la aplicación de las penas, $4^{a}$ edición, Santiago: Editorial Jurídica de Chile, 1992, pp. 145, 162163, 199-201, aludiendo a los aumentos de pena que ordenan los artículos 290, 331 y 400 del Código Penal, respectivamente; CORREA SELAMÉ, Jorge, Aplicación práctica de las penas, Santiago: Editorial Jurídica Aremi, 2011, pp. 398 y 491, haciendo referencia a las agravaciones ordenadas por los artículos 331 y 400 del Código Penal, respectivamente. Un sector de la doctrina afirma que este es el modo en que usualmente los tribunales aumentan los marcos penales compuestos por varios grados. Así, MATUS ACUÑA, Jean Pierre; "Artículos 74 a 78", en: POLITOFF LIFSCHITZ, Sergio; ORTIZ QUIROGA, Luis (Dirs.); MATUS ACUÑA, Jean Pierre (Coord.), Texto y comentario del Código Penal chileno, tomo I, Santiago: Editorial Jurídica de Chile, 2002, pp. 383-407, p. 404. En este sentido, pueden verse, entre otras, las sentencias de la Corte de Apelaciones de San Miguel, de 26 de marzo de 2012, dictada en causa rol N ${ }^{\circ}$ 155-2012, y de la Corte de Apelaciones de Coyhaique, de 4 de junio de 2005, dictada en causa rol $\mathrm{N}^{\circ}$ 37-2005.

${ }^{13}$ Así, NOVOA MONREAL, Curso, cit. nota n 9, p. 358; CURY URZÚA, Enrique, Derecho Penal. Parte General, $10^{a}$ edición, Santiago: Ediciones Universidad Católica de Chile, 2011, p. 762; MATUS ACUÑA, Jean Pierre; VAN WEEZEL, Alex, "Artículos 50 a 73", en: POLITOFF LIFSCHITZ, Sergio; ORTIZ QUIROGA, Luis (Dirs.); MATUS ACUÑA, Jean Pierre (Coord.), Texto y comentario del Código Penal chileno, tomo I, Santiago: Editorial Jurídica de Chile, 2002, pp. 323-382, pp. 368-369; GARRIDO MONTT, Mario, Derecho Penal. Parte General, tomo I, $2^{\text {a }}$ edición, Santiago: Editorial Jurídica de Chile, 2005, p. 320. Parece inclinarse también por esta forma de efectuar el aumento de pena BALMACEDA HOYOS, Gustavo, Manual de Derecho Penal. Parte General, Santiago: Librotecnia, 2014, p. 347. En este mismo sentido, pueden verse, entre otras, las sentencias de la Corte Suprema, de 11 de noviembre de 2013, dictada en causa rol N ${ }^{\circ}$ 7224-2013, y de 19 de abril de 2012, dictada en causa rol No 8784-2011; de la Corte de Apelaciones de San Miguel, de 13 de junio de 2011, dictada en causa rol $\mathrm{N}^{\circ}$ 369-2010; de la Corte de Apelaciones de Santiago, de 7 de septiembre de 2010, dictada en causa rol $\mathrm{N}^{\circ} 1418-2010$, y de la Corte de Apelaciones de La Serena, de 9 de julio de 2010, dictada en causa rol N $174-2010$. 
OLIVER, Guillermo. "Algunos problemas de aplicación de reglas de determinación legal de la pena en el Código Penal chileno".

penas se reduce, primordialmente, a las dos maneras que se acaba de señalar, es posible encontrar varias sentencias que aumentan estas penas de un modo distinto, a partir del grado mínimo, es decir, elevando solo su grado inferior ${ }^{14}$. Por último, una cuarta posibilidad teórica de incrementar esta clase de penas podría consistir en aumentar el límite superior del marco penal compuesto, manteniendo inalterado su límite inferior. Como explico enseguida, el aumento de esta clase de penas debe ser hecho a partir del grado máximo.

Tratándose del incremento que ordena el artículo 351 del Código Procesal Penal para la reiteración de delitos de la misma especie ${ }^{15}$, así lo sugiere una interpretación sistemática que tome en cuenta los efectos que la ley asigna a la concurrencia de dos o más agravantes y ninguna atenuante cuando la pena de un delito consta de dos o más grados (art. 68 inc. $4^{\circ}$ $\mathrm{CP})^{16}$. Imagínese que un delito tenga una pena de presidio menor en sus grados medio a máximo (por ejemplo, el robo por sorpresa, tipificado en el artículo 436 inciso segundo del Código Penal) y que en su comisión concurran dos agravantes y ninguna atenuante. Conforme al artículo 68 del Código Penal, en una situación como ésta, el tribunal tendría dos posibilidades: a) aplicar el efecto que obligatoriamente se prevé para la concurrencia de una agravante, esto es, no imponer el grado mínimo (inc. $2^{\circ}$ ), caso en cual el marco penal disponible sería el de presidio menor en su grado máximo, o bien, b) aplicar el efecto que facultativamente se contempla para la presencia de dos o más agravantes, es decir, imponer la pena inmediatamente superior en grado al máximo (inc. $4^{\circ}$ ), caso en el cual el marco disponible sería el de presidio mayor en su grado mínimo. En otras palabras, si a un robo por sorpresa le acompañan dos agravantes, el tribunal podría aplicar la pena de presidio menor en su grado máximo o la de presidio mayor en su grado mínimo.

Pues bien, si en una reiteración de dos o más robos por sorpresa el aumento de la pena ordenado por el artículo 351 del Código Procesal Penal se hiciera "en bloque", el marco penal resultante del aumento en un grado sería de presidio menor en grado máximo a presidio mayor en grado mínimo, o sea, un marco penal compuesto por exactamente los mismos grados que podría imponer el tribunal en la hipótesis de un solo robo por sorpresa acompañado de dos agravantes. Esto demuestra la incorrección de esta forma de aumentar la pena, ya que conduce al contrasentido de apreciar de la misma manera dos situaciones que, en su esencia, son valorativamente distintas: la de un delito (con dos agravantes) y la de dos o más delitos. El dato accidental de la pluralidad de agravantes no puede pasar por alto la evidente diferencia que existe a nivel de merecimiento y de necesidad de pena, entre la comisión de un solo delito

\footnotetext{
${ }^{14}$ En este sentido, pueden verse las sentencias de la Corte de Apelaciones de Valparaíso, de 26 de septiembre de 2011, dictada en causa rol N 976-2011; de la Corte de Apelaciones de Valdivia, de 15 de julio de 2011, dictada en causa rol $N^{\circ}$ 226-2011, y de la Corte de Apelaciones de Santiago, de 17 de diciembre de 2010, dictada en causa rol $\mathrm{N}^{\circ} 2327-2010$.

${ }^{15}$ Cfr., en el mismo sentido de lo que a continuación expongo en el texto, OLIVER CALDERÓN, Guillermo, "La exasperación de la pena en el concurso material de delitos: la reiteración de delitos de la misma especie", Revista de Derecho, Universidad Austral de Chile, Vol. XXVI, Nº 2 (diciembre 2013), pp. 167-188, pp. 176180.

${ }^{16}$ Una interpretación de esta clase, que lleva a la misma conclusión, realiza CORTÉS ZEPEDA, José Luis, Algunos aspectos de la reiteración de delitos de la misma especie, Seminario de titulación Magíster en Derecho Penal y Ciencias Penales, Pontificia Universidad Católica de Valparaíso, Valparaíso, 2012 (texto inédito de 30 págs.), pp. 21-23.
} 
y la de varios delitos. El aumento de la pena a partir del grado máximo del marco penal compuesto, en cambio, respeta esta diferencia valorativa.

En contra de este planteamiento, se ha señalado que puede producir el mismo contrasentido valorativo que atribuye al denominado aumento "en bloque". Con el fin de demostrarlo, Besio Hernández afirma que:

"si [...] se aumentase en un grado el marco penal asociado a dos delitos reiterados de robo con [sic] sorpresa sin agravantes desde el grado máximo, se generará un marco penal de presidio mayor en su grado mínimo, que es exactamente el mismo marco asignado a un solo delito con dos agravantes, si es que se atribuye a dichas circunstancias su máxima eficacia discrecional admisible normativamente" ${ }^{17}$.

Sin embargo, esta crítica es extremadamente débil como defensa del incremento "en bloque", ya que el contrasentido que denuncia (un delito tendría la misma pena que dos o más delitos), siendo real, es evidentemente menor que el que se produce cuando se compara la pena de un robo por sorpresa con dos agravantes a las que se atribuye su máxima eficacia (presidio mayor en su grado mínimo), con la de dos o más robos por sorpresa reiterados cuyo incremento en un grado se efectúa "en bloque" (presidio menor en su grado máximo a presidio mayor en su grado mínimo) (un delito tendría más pena que dos o más delitos).

Además, el incremento de pena "en bloque" presenta el problema de que distorsiona el sistema de exasperación que subyace al citado artículo 351, al permitir la aplicación de una pena que ya estaba comprendida dentro del marco penal disponible antes de efectuar el aumento. Retomando el ejemplo de la reiteración de dos o más robos por sorpresa, si se aumentara de esta manera la pena en un grado, se llegaría a la de presidio menor en grado máximo a presidio mayor en su grado mínimo, dejando al tribunal la posibilidad de imponer uno u otro grado. Si decidiera aplicar presidio menor en su grado máximo -lo que no sería inusual, dada la tendencia de nuestros tribunales a imponer las penas en su grado mínimo y, dentro de éste, en el mínimo-, estaría imponiendo una pena que ya estaba incluida en el marco penal antes de aumentarlo, con lo que, en definitiva, éste no se habría realmente exasperado ${ }^{18}$ y habría sido objeto sólo de una forma de absorción agravada, como la que prevé el artículo 75 del Código

17 BESIO HERNÁNDEZ, Martín, “Aplicación del artículo 351 del Código Procesal Penal”, Política Criminal, Vol. 10, № 20 (diciembre 2015), pp. 543-596, p. 573.

18 MAÑALICH RAFFO, Juan Pablo, "La reiteración de hechos punibles como concurso real. Sobre la conmensurabilidad típica de los hechos concurrentes como criterio de determinación de la pena", Política Criminal, Vol. 10, $\mathrm{N}^{\circ} 20$ (diciembre 2015), pp. 498-527, p. 517, n. 60, no tanto en defensa del denominado aumento "en bloque", sino más bien en contra del aumento a partir del grado máximo, afirma que la ley no define lo que significa exasperar una pena y que "nada inconsistente hay en entender que, por la vía de desplazar hacia arriba, en uno o dos grados, cada uno de los grados o penas que integran el correspondiente marco compuesto, en efecto se sobrepasa el límite superior de la pena disponible, precisamente porque, en este contexto, la 'pena' objeto de exasperación se identifica con el marco compuesto". Un planteamiento similar efectúa BESIO HERNÁNDEZ, “Aplicación”, cit. nota n 17, pp. 574-575. Si bien es cierto que la ley no define lo que significa exasperar un marco penal compuesto, la comprensión de Mañalich Raffo y Besio Hernández acerca de tal significado, al menos para el caso del artículo 351 del Código Procesal Penal, tiende a difuminar su diferencia con la regla de la absorción agravada, al permitir la imposición de una pena ya comprendida en el marco penal antes de aumentarlo, y pasa por alto que la ley reserva esta última regla de penalidad para un caso concursal muy distinto y portador de un menor desvalor. 
OLIVER, Guillermo. “Algunos problemas de aplicación de reglas de determinación legal de la pena en el Código Penal chileno".

Penal, pero para una hipótesis que es muy distinta, cual es la del concurso ideal de delitos ${ }^{19}$, regla de castigo que se justifica para esta clase de concurso en atención al menor desvalor de acción que hay cuando mediante una sola conducta se cometen dos o más delitos ${ }^{20}$; en el artículo 351 del Código Procesal Penal, en cambio, las conductas sancionadas son varias, por lo que el incremento debe traducirse en la imposición de una pena superior al grado máximo. Como afirma Cuerda Riezu, "rasgo característico de la exasperación es [...] sobrepasar el límite superior de la pena disponible"21. A diferencia del aumento de pena "en bloque", el incremento desde el grado máximo de la pena compuesta respeta el sistema de exasperación ${ }^{22}$.

Por este mismo motivo, tampoco son aceptables las otras dos formas posibles de efectuar el aumento de un marco penal compuesto por dos o más grados: la que lo realiza desde el grado mínimo $^{23}$ y la que, conservando intacto el límite inferior, eleva el superior. Esta última posibilidad, además, plantea el problema, especialmente cuando se trata de marcos penales compuestos por más de dos grados, de que puede originar un marco demasiado amplio ${ }^{24}$ y difícilmente compatible con el principio de taxatividad de la ley penal ${ }^{25}$, aun admitiendo que

${ }^{19}$ Subraya la diferencia entre la agravación de pena que ordena la regla de la reiteración de delitos de la misma especie y la que impone el artículo 75 del Código Penal, FONTECILLA RIQUELME, Rafael, Concursos de delincuentes, de delitos y de leyes penales y sus principales problemas jurídicos, Santiago: Editorial Jurídica de Chile, 1956, p. 80, quien, al aludir al artículo 509 del Código de Procedimiento Penal (en rigor, sólo a su primer inciso), pero con una argumentación igualmente aplicable al artículo 351 del Código Procesal Penal, afirma que "el aumento de pena, en este caso, excede del grado señalado por la ley; mientras que en el concurso ideal permanece dentro del grado, aplicándose la pena sólo en su máximo”.

${ }^{20}$ Por todos, véase VARGAS PINTO, Tatiana, Manual práctico de aplicación de la pena, Santiago: Thomson Reuters Legal Publishing, 2014, p. 172.

${ }^{21}$ CUERDA RIEZU, Antonio, Concurso de delitos y determinación de la pena, Madrid: Tecnos, 1991, p. 116.

${ }^{22}$ Similar, CORTÉS ZEPEDA, Algunos aspectos, cit. nota ${ }^{\circ} 16$, p. 24.

Si bien es cierto que el aumento de la pena desde el grado máximo se traducirá en que muchas veces resultará más conveniente para el imputado el sistema de acumulación aritmética previsto en el artículo 74 del Código Penal, ello no siempre será así, por lo que no puede verse en esto un argumento en contra de la interpretación propuesta; mi planteamiento no conduce a una inaplicación del artículo 351 del Código Procesal Penal. Aun efectuándose de esta manera el incremento ordenado por esta última disposición, será para el imputado más favorable que la acumulación aritmética, en casos como los tenidos en cuenta por comentaristas de fines del siglo XIX que criticaban las exorbitantes penas que en ocasiones se imponían para reiteraciones de muchos delitos, al amparo del citado artículo 74, cuando todavía no existía el artículo 509 del Código de Procedimiento Penal de 1907, antecedente del referido artículo 351. Cfr., por ejemplo, CORREA BRAVO, Agustín, "Ochenta y cuatro años de presidio", Revista Forense Chilena, Vol. 4 (1888), pp. 507-511, quien aludía al caso de una persona que fue condenada a veintiocho penas de tres años y un día de presidio menor en su grado máximo cada una, por veintiocho delitos de falsificación de documento público por empleado público (art. $193 \mathrm{CP}$ ), lo que arrojaba la suma de ochenta y cuatro años y veintiocho días de privación de libertad.

${ }^{23}$ Véase la sentencia de la Corte Suprema, de 11 de noviembre de 2013, dictada en causa rol N ${ }^{\circ} 7224-2013$, la que, admitiendo como posibles, tanto el aumento "en bloque", como el efectuado a partir del grado máximo, rechaza expresamente, por razones valorativas, la procedencia del aumento desde el grado mínimo del marco penal compuesto.

${ }^{24}$ Así, CALDERÓN ORTIZ, Carmen, Algunos aspectos de la regla de punición de la reiteración de delitos de la misma especie, Pontificia Universidad Católica de Valparaíso, Valparaíso, 2013, p. 34.

${ }^{25}$ Esto último puede objetarse a MAÑALICH RAFFO, “La reiteración”, cit., nota n 18, p. 516, n. 60, quien criticando la interpretación sistemática hecha más arriba a partir de los efectos que la ley atribuye a la concurrencia de dos o más agravantes y ninguna atenuante cuando la pena de un delito consta de dos o más grados, parece considerar posible, a mi juicio, contra legem, una interpretación del artículo 68 inciso cuarto 
Polít. crim. Vol. 11, No 22 (Diciembre 2016), Art. 13, pp. 766-793.

[http://www.politicacriminal.cl/Vol_11/n_22/Vol11N22A13.pdf]

en el establecimiento de las penas puede haber una mayor flexibilidad que en la descripción del comportamiento típico, para alcanzar fines de prevención especial ${ }^{26}$.

Ahora bien, dejando a un lado los casos de reiteración de delitos de la misma especie, las restantes hipótesis en que procede aumentar en grado la pena asignada a un tipo, compuesta por dos o más grados, se basan en circunstancias modificatorias. Así sucede, por ejemplo, con el aumento de un grado que permite el inciso cuarto del artículo 68 del Código Penal, cuando no concurriendo circunstancias atenuantes, hay dos o más agravantes, caso en el cual la ley establece que el aumento es hecho desde el grado máximo de la pena. Otro tanto puede ocurrir con ciertas agravantes de efecto extraordinario que, haciendo excepción a la regla que se extrae de los artículos 65 a 68 del mismo Código en el sentido de que una sola agravante no permite aumentar la pena en grado, unas veces facultan y otras ordenan elevar la pena en un grado, aunque sin explicitar la manera de hacer el aumento. Es lo que acontece, verbigracia, en los artículos 72, 290, 331 y 400 del citado texto normativo.

Pues bien, una argumentación sistemática conduce a la conclusión de que, en estos últimos casos, la pena también debe aumentarse desde el grado máximo. Si conforme a lo dispuesto en los artículos 67 y 68 del Código Penal, es sólo una pluralidad de agravantes la que permite incrementar la sanción en un grado, y cuando se trata de una pena compuesta por varios grados tal aumento se traduce en la imposición del grado inmediatamente superior al máximo de los designados por la ley (art. 68 inc. $4^{\circ}$ ), sería absurdo concluir que cuando ésta ha querido endurecer el tratamiento punitivo de un hecho, estableciendo una agravante que, excepcionalmente, sirve por sí sola para aumentar la pena en grado, la aplicación de dicha agravación a un marco penal compuesto por varios grados tuviera que traducirse en un aumento "en bloque", ya que esto haría posible imponer una pena inferior a la aplicable en el régimen general de agravación. La decisión legal de atribuir a una sola agravante el efecto de aumentar la pena de un delito en un grado, cuando su marco penal se compone de dos o más, sin explicitar la manera de hacerlo, no debe interpretarse contrario sensu como una excepción a la forma de hacer el aumento de la sanción que establece el inciso cuarto del artículo 68 del Código Penal, sino como una excepción a la regla de que para aumentar la pena deben concurrir dos o más agravantes.

En todo caso, en esta línea argumentativa carece de interés determinar si estas circunstancias, que por sí solas sirven para aumentar la pena en grado, son agravantes de efecto extraordinario o, más bien, figuras calificadas de un tipo básico ${ }^{27}$. Incluso si se las considerara como

del Código Penal que entienda que en este caso "el respectivo marco penal sea ampliado de manera tal que pase a integrar, asimismo, el grado superior al máximo de los grados originalmente previstos por la ley". Especialmente crítico frente a marcos penales demasiado extensos se muestra ÁLVAREZ GARCÍA, Francisco Javier, "La determinación legislativa de la pena privativa de libertad", Poder Judicial, Vol. 56 (1999), pp. 35-62, pp. 41-43. Exponiendo argumentos a favor y en contra de esta clase de marcos penales, véase POSADA MAYA, Ricardo; HERNÁNDEZ BELTRÁN, Harold M., El sistema de individualización de la pena en el Derecho penal colombiano, Medellín: Universidad Pontificia Bolivariana - Biblioteca Jurídica Diké, 2001, pp. 307-314.

${ }^{26}$ Cfr. ZUGALDÍA ESPINAR, José Miguel, Fundamentos de Derecho Penal, $3^{\mathrm{a}}$ edición, Valencia: Tirant lo Blanch, 1993, p. 284.

${ }^{27}$ Sobre el tema relativo a cómo distinguir entre calificantes y privilegiantes, por un lado, y agravantes y atenuantes de efecto extraordinario, por otro, véase COUSO SALAS, Jaime, "Comentario al art. 50", en: COUSO SALAS, Jaime; HERNÁNDEZ BASUALTO, Héctor (Dirs.), Código Penal Comentado. Parte 
OLIVER, Guillermo. "Algunos problemas de aplicación de reglas de determinación legal de la pena en el Código Penal chileno".

calificantes, el argumento subsistiría y con mayor razón. No tendría sentido que mientras dos circunstancias agravantes de efecto común permiten imponer el grado inmediatamente superior al máximo de los designados por la ley a un delito, cuando ésta decide crear una calificante que faculta $\mathrm{u}$ ordena el aumento en un grado del marco penal compuesto de una figura básica, dicho aumento tuviera que hacerse "en bloque". La interpretación de la ley no debe llevar a que un hecho más grave (la realización de un tipo penal calificado) reciba un tratamiento punitivo de menor intensidad (la asignación de un marco penal más benigno) que uno menos grave (la realización de su respectivo tipo básico, concurriendo dos circunstancias agravantes).

A todo lo anterior debe agregarse, por un lado, que el aumento a partir del grado máximo de los marcos penales compuestos por varios grados, cualquiera sea la razón por la cual proceda su incremento, se muestra más coherente con el sistema del Código Penal, en el que, como se ha dicho, la rebaja de tales marcos debe ser efectuada siempre a partir de su grado mínimo. No se aprecia una razón lógica para sustentar un criterio distinto en la forma de incrementar dichos marcos ${ }^{28}$. Y, por otro lado, que el aumento desde el grado máximo se muestra más respetuoso de la igualdad ante la ley, porque supone tratar al imputado de la misma manera que como se trata al condenado por un delito cuyo marco penal se integra solo por un grado, quien después de efectuado el incremento de uno o más grados de pena, no puede recibir (salvo por la concurrencia de atenuantes) una sanción que estaba comprendida en el marco original $^{29}$.

Quienes se han mostrado partidarios del denominado aumento "en bloque" han sostenido, básicamente, tres argumentos: en primer lugar, que como cada grado de una pena divisible constituye una pena distinta (art. $57 \mathrm{CP}$ ), el incremento de una pena compuesta por varios grados debería abarcar la integridad de los mismos y no recaer solo sobre la pena más alta ${ }^{30}$; en segundo término, que sería procedente realizar una interpretación contrario sensu de lo dispuesto en el inciso cuarto del artículo 68 del Código Penal en la resolución de cualquier caso de aumento de un marco penal compuesto por dos o más grados que no obedezca a la concurrencia de dos o más agravantes comunes, y por último, que el aumento desde el grado máximo da lugar a un solo grado de pena, lo que supondría un perjuicio para el imputado desde el punto de vista del número de grados en que después del incremento puede rebajarse el marco penal por la concurrencia de atenuantes, porque cuando se trata de un grado de pena divisible, se permite una rebaja de solo dos grados (art. 67 inc. $4^{\circ} \mathrm{CP}$ ), en tanto que si se trata de una pena compuesta por dos o más grados, se permite una rebaja de hasta tres grados (art. 68 inc. $\left.3^{\circ} \mathrm{CP}\right)^{31}$.

El argumento esgrimido a partir de lo dispuesto en el artículo 57 del Código Penal no es de recibo. Cuando se aumenta un marco penal compuesto por varios grados a partir del grado

General. Doctrina y Jurisprudencia, Santiago: Abeledo Perrot Legal Publishing Chile, 2011, pp. 524-544, pp. 525-531.

${ }^{28}$ Cfr. ORTIZ QUIROGA/ARÉVALO CUNICH, Las consecuencias, cit. nota n ${ }^{\circ} 12$, p. 292.

${ }^{29}$ Así, CORTÉS ZEPEDA, Algunos aspectos, cit. nota n 16, p. 24.

${ }^{30}$ En este sentido, en referencia al aumento de penas que ordena el artículo 351 del Código Procesal Penal, BESIO HERNÁNDEZ, “Aplicación”, cit. nota n 17, p. 574.

${ }^{31}$ Cfr. NOVOA MONREAL, Curso, cit. nota n ${ }^{\circ} 9$, pp. 357-358. 
máximo no se infringe lo previsto en tal precepto, porque éste no impide entender que dicho aumento deba traducirse en la imposición de una pena superior a todo ese marco y no solo a una de sus partes. La formulación de semejante argumento sugiere que sería inconsistente que se incrementara en un grado a partir del grado máximo un marco penal compuesto, porque en tal evento la pena que se impondría sería superior en un grado solo al más alto de los que conforman dicho marco, pero superaría en dos o más grados a cada uno de los restantes grados del mismo. Lo cierto es que ello no representa ninguna inconsistencia en el sistema de determinación legal de la pena del Código Penal, toda vez que, por ejemplo, cuando la ley obliga a rebajar en un grado la pena señalada para el autor de delito consumado, a los cómplices de delito consumado o a los autores de delito frustrado (art. 51 CP), tal rebaja se traduce en la imposición de una pena inferior en un grado a la correspondiente al autor de delito consumado únicamente cuando esta pena es una indivisible o un grado de pena divisible, ya que cuando se compone de varios grados, dicha rebaja es inferior en un grado solo al más bajo de ellos, siendo inferior en dos o más grados a cada uno de los demás (art. 61 $\operatorname{regla} 2^{\mathrm{a}}$ ).

El argumento consistente en la necesidad de efectuar una interpretación contrario sensu de lo previsto en el inciso cuarto del artículo 68 del Código Penal tampoco puede aceptarse. No hay ninguna razón que avale semejante interpretación para los aumentos de marcos penales compuestos que no se deban a la concurrencia de dos o más agravantes comunes. Si bien se podría también asumir un punto de vista inverso y plantear que dicha disposición consagra de modo general la forma de efectuarse el aumento de las penas compuestas por dos o más grados, lo realmente decisivo es que el aumento a partir del grado máximo de estas penas produce menos contrasentidos valorativos que otras formas de incrementarlas y no distorsiona el sistema de exasperación que subyace al artículo 351 del Código Procesal Penal, además de que se ajusta mejor a la razón por la cual la ley ha establecido ciertas agravantes que por sí solas sirven para aumentar la pena en grado sin señalar la manera de hacerlo, como se ha explicado más arriba.

El tercer argumento tampoco es de recibo. Tratándose del aumento de penas que prevé el artículo 351 del Código Procesal Penal, no lo es, porque las circunstancias modificatorias concurrentes deben ser consideradas antes de efectuar tal incremento. Ello es así, no solo al aplicarse el segundo inciso de dicho precepto, el que expresamente alude a la estimación de tales circunstancias antes de la exasperación de la pena, sino también al aplicarse su primer inciso, a pesar de que éste guarda silencio sobre el punto ${ }^{32}$. Y cuando se trata del aumento

\footnotetext{
${ }^{32}$ No puedo explicar aquí las razones de esta afirmación, la que es sostenida, entre otros, por OLIVER CALDERÓN, "La exasperación”, cit. nota n 15, pp. 175-176; CONTRERAS GUERRERO, Pablo, "Una tesis para entender la medida de la pena en los casos de reiteración de delitos de la misma especie: análisis de las reglas penológicas contenidas en el artículo 351 del Código Procesal Penal a la luz del principio de proporcionalidad constitucional", Política Criminal, Vol. 9, № 18 (diciembre 2014), pp. 614-667, pp. 656657; BESIO HERNÁNDEZ, "Aplicación”, cit. nota $\mathrm{n}^{\circ}$ 17, pp. 578-580; COUSO SALAS, Jaime, "Comentario previo a los arts. 74 y 75. El régimen concursal en el Derecho chileno. Tratamiento doctrinario y jurisprudencial”, en: COUSO SALAS, Jaime; HERNÁNDEZ BASUALTO, Héctor (Dirs.), Código Penal Comentado. Parte General. Doctrina y Jurisprudencia, Santiago: Abeledo Perrot Legal Publishing Chile, 2011, pp. 625-666, pp. 651-652; SOLARI PERALTA, Tito; RODRÍGUEZ COLLAO, Luis, "Determinación de la pena en los casos de reiteración de delitos (ámbito de aplicación del artículo 509 del Código de Procedimiento Penal)", Revista de Derecho, Universidad Católica de Valparaíso, Vol. 3 (1979), p. 265; VIVANCO SEPÚLVEDA, Jaime, "Manera y oportunidad de aumentar la pena en caso de reiteración de
} 
OLIVER, Guillermo. "Algunos problemas de aplicación de reglas de determinación legal de la pena en el Código Penal chileno".

debido a ciertas agravantes de efecto extraordinario, el argumento tampoco es macizo, porque subyace a su formulación la idea de que cuando concurren circunstancias modificatorias comunes o de eficacia ordinaria junto con circunstancias especiales o de eficacia extraordinaria, éstas deberían aplicarse antes que aquéllas. No resulta posible sostener esta última aseveración, a la luz de la muy escasa atención que la doctrina nacional ha dedicado al tema del orden en que deben aplicarse las reglas que alteran la pena señalada por la ley al delito $^{33}$. Incluso, dentro del exiguo tratamiento doctrinal de este tema, puede advertirse cierta tendencia a afirmar exactamente lo contrario a lo que subyace a esta crítica, planteando la necesidad de considerar primero las circunstancias modificatorias comunes o de eficacia ordinaria y las reglas de los artículos 65 a 68 bis del Código Penal, y luego las circunstancias de eficacia extraordinaria con sus reglas especiales ${ }^{34}$.

Desde luego, mi planteamiento acerca de la manera de aumentar los marcos penales compuestos por varios grados no constituye una aplicación analógica (perjudicial) de lo dispuesto en el artículo 68 inciso cuarto del Código Penal a los casos en que la ley ordena o faculta un aumento de penas compuestas por dos o más grados sin indicar la forma de efectuar tal incremento, porque no implica desbordar los límites del sentido literal máximo posible de las disposiciones que establecen dicho aumento, por lo que sólo podría ser considerado como una interpretación extensiva, forma de interpretación que es comúnmente admitida al entender que el denominado principio pro reo no es aplicable en la interpretación de la ley penal ${ }^{35}$. Ni siquiera podría reprocharse dicho carácter extensivo en el caso del aumento de penas que

delitos de la misma especie. Comentario a sentencia de Corte Suprema de 9 de junio de 1970", Revista de Ciencias Penales, Vol. 29, № 3 (septiembre - diciembre 1970), p. 261, aludiendo estos últimos al artículo 509 del Código de Procedimiento Penal, pero con una argumentación plenamente aplicable al artículo 351 del Código Procesal Penal. También MAÑALICH RAFFO, "La reiteración", cit., nota $n^{\circ} 18$, pp. 521-522, aunque afirmando que los incisos primero y segundo del artículo 351 establecen dos distintos regímenes de determinación de pena, lo que los autores antes citados niegan. En contra de considerar las circunstancias modificatorias antes de la exasperación en el caso del inciso primero, MALDONADO FUENTES, Francisco, "Reiteración y concurso de delitos. Consideraciones sobre el artículo 351 del Código Procesal Penal a partir de la teoría general del concurso de delitos en el Derecho chileno", en: CÁRDENAS ARAVENA, Claudia; FERDMAN NIEDMANN, Jorge (Coords.), El Derecho penal como teoría y como práctica. Libro en homenaje a Alfredo Etcheberry Orthusteguy, Santiago: Thomson Reuters - Legal Publishing, 2016, pp. 549607, pp. 597-598; implícitamente, ORTIZ QUIROGA/ARÉVALO CUNICH, Las consecuencias, cit. nota ${ }^{\circ}$ 12, p. 340.

${ }^{33}$ Constata esta falta de ocupación doctrinal sistemática del problema, COUSO SALAS, "Comentario al art. $50 "$, cit. nota n ${ }^{\circ} 27$, p. 532.

${ }^{34}$ Así, ETCHEBERRY, Alfredo, Derecho Penal. Parte General, tomo II, $3^{\text {a }}$ edición, Santiago: Editorial Jurídica de Chile, 1998, pp. 189-190; MATUS ACUÑA/VAN WEEZEL, “Artículos 50 a 73”, cit. nota n 13, pp. 362-363; VAN WEEZEL, "Compensación", cit. nota n 6, p. 500. En contra, a propósito de la agravante especial del artículo 400 del Código Penal, MATUS ACUÑA, Jean Pierre; RAMíREZ GUZMÁN, María Cecilia, Lecciones de Derecho Penal Chileno. Parte Especial, $3^{\text {a }}$ edición, Santiago: Thomson Reuters - Legal Publishing, 2014, p. 137. Declara la necesidad de "resolver el orden caso a caso, según si del tenor literal o de la ratio legis, en su defecto, se desprende con claridad que el sentido del precepto que establece un especial efecto agravatorio o atenuatorio para una determinada circunstancia, es que debe operar sobre una pena ya determinada en concreto (hasta antes de aplicar el Art. 69), o sobre el marco penal abstracto", COUSO SALAS, "Comentario al art. 50", cit. nota n ${ }^{\circ} 27$, pp. 536-537 (las cursivas en el original).

${ }^{35}$ Cfr., entre otros, ETCHEBERRY, Alfredo, Derecho Penal. Parte General, tomo I, $3^{\text {a }}$ edición, Santiago: Editorial Jurídica de Chile, 1998, pp. 109-110; CURY URZÚA, Derecho Penal, cit. nota ${ }^{\circ}$ 13, p. 197; GARRIDO MONTT, Derecho, cit. nota n ${ }^{\circ} 13$, pp. 104-105; POLITOFF LIFSCHITZ, Sergio, Derecho Penal, tomo I, Santiago: Editorial Jurídica Conosur, 1997, pp. 133-134. 
Polít. crim. Vol. 11, No 22 (Diciembre 2016), Art. 13, pp. 766-793.

[http://www.politicacriminal.cl/Vol_11/n_22/Vol11N22A13.pdf]

ordena efectuar el artículo 351 del Código Procesal Penal, argumentando que, atendida la ubicación de este precepto, le sería aplicable lo dispuesto en el artículo $5^{\circ}$ del mismo cuerpo legal, según el cual "[1]as disposiciones de este Código que autorizan la restricción de la libertad o de otros derechos del imputado o del ejercicio de alguna de sus facultades serán interpretadas restrictivamente y no se podrán aplicar por analogía"36. Ello es así, porque esta última disposición también debe ser interpretada, y su ubicación, al igual que su epígrafe ("Legalidad de las medidas privativas o restrictivas de libertad") sugieren fuertemente que su ámbito de aplicación es sólo el de las medidas coercitivas que durante el proceso penal pueden decretarse contra el imputado, tales como las medidas cautelares y las diligencias intrusivas, no el de una regla de determinación de pena como el citado artículo 351.

En otro orden de ideas, un sector de la doctrina llama la atención acerca del hecho de que al efectuar rebajas en las escalas graduales del artículo 59 del Código Penal, pueden resultar ciertos desequilibrios, ya que una pena inmediatamente inferior en grado a otra podría resultar más gravosa que ella. Por ejemplo, se cita, en la escala $\mathrm{N}^{\circ} 2$, el caso de la relegación menor en su grado mínimo, que tras la rebaja de un grado da lugar al destierro en su grado máximo, y en la escala $\mathrm{N}^{\circ} 3$, el caso del confinamiento o extrañamiento menor en su grado mínimo, que después de la disminución de un grado también se convierte en destierro en su grado máximo ${ }^{37}$. Para superar este problema, algunos han propuesto que en estos casos el tribunal no haga rebaja alguna o, si es posible, rebaje más grados hasta llegar al destierro en su grado mínimo $^{38}$, en tanto que otros han sugerido realizar consideraciones similares a las que se efectúan cuando se determina qué ley resulta más favorable en las hipótesis de sucesión de leyes penales ${ }^{39}$.

Debe concordarse en que, si en estos casos la rebaja de que se trata fuera facultativa, o si fuera obligatoria, pero permitiera arribar hasta el destierro en su grado mínimo, cualquiera de las dos soluciones propuestas sería de recibo. No obstante, cuando la pena de destierro en su grado máximo es ineludible, no queda más remedio que imponerla, en obsequio al principio de legalidad, que impide que en la interpretación de la ley penal se sobrepase el límite de su literalidad; corresponde al legislador salvar esta aparente asimetría. En todo caso, bien podría cuestionarse que se trate de un verdadero desequilibrio, ya que el destierro importa una restricción de la libertad del condenado, de menor intensidad que la que implican el confinamiento, el extrañamiento y la relegación (arts. 33-36 CP).

Por otra parte, resulta llamativo el hecho de que ciertas penas se encuentren en más de una escala. Es lo que sucede, por ejemplo, con la pena de destierro, que se halla en los números $8^{\circ}$, $9^{\circ}$ y 10 de la escala $\mathrm{N}^{\circ} 2$ y en los números $7^{\circ}, 8^{\circ}$ y $9^{\circ}$ de la escala $\mathrm{N}^{\circ} 3$, y la pena de suspensión, que ocupa los lugares $5^{\circ}, 6^{\circ}$ y $7^{\circ}$ en la escala $\mathrm{N}^{\circ} 4$ y los mismos lugares en la

\footnotetext{
${ }^{36}$ Un reproche de esta clase efectúa, contra la interpretación que en el caso del artículo 351 del Código Procesal Penal postula el aumento desde el grado máximo, BESIO HERNÁNDEZ, "Aplicación", cit. nota n 17, p. 570, quien no advierte la posibilidad de una interpretación restrictiva del citado artículo $5^{\circ}$, como la que esbozo a continuación en el cuerpo de este trabajo.

${ }^{37}$ Ejemplos citados por PICA URRUTIA, Reglas, cit. nota ${ }^{\circ} 12$, pp. 13-14.

${ }^{38}$ PICA URRUTIA, Reglas, cit. nota ${ }^{\circ} 12$, p. 14.

39 Así, COUSO SALAS, Jaime, "Comentario al art. 59", en: COUSO SALAS, Jaime; HERNÁNDEZ BASUALTO, Héctor (Dirs.), Código Penal Comentado. Parte General. Doctrina y Jurisprudencia, Santiago: Abeledo Perrot Legal Publishing Chile, 2011, pp. 552-558, p. 555.
} 
OLIVER, Guillermo. "Algunos problemas de aplicación de reglas de determinación legal de la pena en el Código Penal chileno".

escala $\mathrm{N}^{\circ} 5^{40}$. Esto puede producir un problema, ya que, al efectuar aumentos de grado a partir de dichas penas en las respectivas escalas graduales, se llega a resultados distintos, según se tome como referencia una u otra escala. En materia de destierro, el punto no es preocupante, porque, al menos en el texto actualmente vigente del Código Penal, después de la despenalización de los delitos de adulterio y amancebamiento, hecha en 1994 mediante la Ley $\mathrm{N}^{\circ} 19.335$, no existe ningún tipo que contemple dicha sanción ${ }^{41}$. Pero el problema sí puede plantearse con la suspensión de cargo u oficio público o profesión titular, ya que en dicho Código son varios los delitos que se castigan con esta sanción como pena principal (única, copulativa o alternativa), especialmente en el Párrafo 4 del Título III y en el Título V de su Libro Segundo, como ocurre, por ejemplo, en los delitos de detención ilegal (art. 148), violación de domicilio por empleado público (art. 155), prevaricación judicial culposa (art. 225), prevaricación administrativa (art. 228), omisión del deber de perseguir delincuentes (art. 229), prevaricación de abogado o procurador (art. 231), malversación culposa (art. 234), malversación por distracción sin daño ni entorpecimiento del servicio público (art. 235 inc. $3^{\circ}$ ), malversación por aplicación pública diferente (art. 236), malversación por negativa de pago o de entrega de una cosa (art. 237), violación de secretos (art. 246 inc. $1^{\circ}$ ), cohecho (art. 248), denegación de auxilio y abandono de destino (arts. 253 inc. $1^{\circ}$ y 254 inc. $1^{\circ}$ ) y abusos contra particulares (arts. 255 y 256), entre otros.

En estos casos, el aumento de grados a partir de la pena de suspensión debería realizarse, tanto en la escala $\mathrm{N}^{\circ} 4$, como en la $\mathrm{N}^{\circ}$ 5. De ese modo, se podrá llegar a dos penas posibles de ser impuestas: una inhabilitación absoluta, conforme a aquella escala, o una inhabilitación especial, conforme a ésta. En otras palabras, se tratará de un supuesto especial de penas alternativas $^{42}$, en cuya elección deberán ser utilizados los mismos criterios que señalo más abajo para hipótesis de penas alternativas explícitamente contempladas por la ley al sancionar ciertos delitos.

Por otro lado, como es sabido, si por aplicación del mecanismo que permite aumentar grados de pena se llega al tope máximo de la respectiva escala y todavía es necesario seguir subiendo, se aplican las siguientes reglas, contempladas en el artículo 77 del Código Penal: en la escala $\mathrm{N}^{\circ} 1$, debe imponerse la pena de presidio perpetuo calificado (inciso segundo) (más bien, se la debe mantener, ya que ésa es, precisamente, la pena superior de dicha escala); en las escalas $\mathrm{N}^{\circ} 2$ y $\mathrm{N}^{\circ} 3$, debe imponerse la pena de presidio perpetuo (inciso segundo), y en las escalas $\mathrm{N}^{\circ}$ $4 \mathrm{y} \mathrm{N}^{\circ} 5$, se debe imponer la sanción superior de la respectiva escala y, además, la pena de reclusión menor en su grado medio (inciso cuarto).

\footnotetext{
${ }^{40}$ Lo observa ETCHEBERRY, Derecho, tomo II, cit. nota n 34, p. 172.

${ }^{41}$ Cfr. GUZMÁN DALBORA, José Luis, La pena y la extinción de la responsabilidad penal, Santiago: Legal Publishing, 2008, p. 230; NÁQUIRA RIVEROS, Jaime et alii, "Principios y penas en el Derecho penal chileno", Revista Electrónica de Ciencia Penal y Criminología, Universidad de Granada, Vol. 10 (2008), p. 36.

${ }^{42}$ La misma idea sugiere GARCÍA ARÁN, Mercedes, Los criterios de determinación de la pena en el Derecho español, Barcelona: Ediciones de la Universidad de Barcelona, 1982, pp. 41-42, quien, comentando el hecho de que en el Código Penal español de 1870 la pena de muerte aparecía encabezando más de una escala, señala que ello "responde quizás a la preocupación [...] de ofrecer la posibilidad de que desde la pena de muerte se descendiera por dos escalas distintas: por aquella que recoge penas en las que predomina el carácter aflictivo (cadena y presidio, que llevan consigo la prestación de trabajo forzoso) y por aquella cuyas penas son exclusivamente consistentes en privación de libertad (reclusión y prisión)”.
} 
Polít. crim. Vol. 11, No 22 (Diciembre 2016), Art. 13, pp. 766-793.

[http://www.politicacriminal.cl/Vol_11/n_22/Vol11N22A13.pdf]

Un sector de la doctrina parece sugerir que en este último caso (escalas $\mathrm{N}^{\circ} 4$ y $\mathrm{N}^{\circ}$ ), la pena de reclusión menor en su grado medio se impone en vez de la pena superior de la respectiva escala $^{43}$. Esta interpretación no es de recibo, ya que a diferencia del segundo inciso del artículo 77 del Código Penal, el cual señala que cuando no haya pena superior en la escala gradual respectiva "se impondrá" el presidio perpetuo, y en la escala $\mathrm{N}^{\circ} 1$, el presidio perpetuo calificado, el inciso cuarto del mismo precepto indica que las inhabilitaciones absolutas o especiales perpetuas "se agravarán" con la reclusión menor en su grado medio. Esta última expresión no puede significar otra cosa que la aplicación conjunta de las respectivas penas de inhabilitación y reclusión ${ }^{44}$. Esta idea se reafirma si se tiene presente que, según lo dispuesto en el artículo 30 del Código Penal, la pena de reclusión menor en su grado medio lleva consigo la de suspensión de cargo u oficio público durante el tiempo de la condena. Sería absurdo entender que cuando la ley sanciona un delito cometido por empleado público en el ejercicio de sus funciones con inhabilitación perpetua -la pena más alta de las escalas $\mathrm{N}^{\circ} 4 \mathrm{y}$ $\mathrm{N}^{\circ}$ 5- (como, por ejemplo, el delito de denegación de auxilio con grave daño a la causa pública, del artículo 253 inciso segundo del Código Penal), y por la concurrencia de agravantes es necesario aumentar dicha pena, la agravación tuviera que traducirse, en lo que a la protección de la función pública respecta, sólo en una prohibición temporal de ejercer el cargo u oficio público que el condenado servía, impuesta como pena accesoria a la reclusión.

Sin embargo, hay buenas razones para afirmar que cuando las inhabilitaciones perpetuas aparecen como penas copulativas junto con penas privativas de libertad, éstas "absorben" a las que se derivarían de la agravación de aquéllas ${ }^{45}$; en otras palabras, que en estos casos la agravación de las penas superiores de las escalas $\mathrm{N}^{\circ} 4$ y $\mathrm{N}^{\circ} 5$ no tiene lugar. La finalidad del último inciso del artículo 77 del Código Penal es la de agravar la inhabilitación perpetua mediante la imposición de una pena privativa de libertad adicional, cuando se trata de delitos que no contemplan esta última clase de sanción, como ocurre, por ejemplo, con la prevaricación de abogado (art. $232 \mathrm{CP}$ ), la figura agravada de cohecho de funcionario para la comisión de delitos ministeriales (art. 249 inc. $1^{\circ} \mathrm{CP}$ ) y el tipo agravado de denegación de auxilio (art. 253 inc. $2^{\circ} \mathrm{CP}$ ). Pero cuando la inhabilitación perpetua acompaña a una pena privativa de libertad (como sucede, verbigracia, en los delitos tipificados en los artículos 150 A inciso final, 223, 240 bis, 259 inciso segundo, 269 ter, 464 y 464 bis del Código Penal), la agravación de aquélla pierde sentido, especialmente si se considera que el aumento de ésta en un grado conduce siempre - de acuerdo con la forma que estimo correcta de incrementar los marcos penales compuestos por dos o más grados- a la imposición de una pena más grave que la reclusión menor en su grado medio, lo que avala la tesis de la "absorción".

Ahora bien, sabido es que si, efectuando rebajas de pena, se llega al tope mínimo de la respectiva escala y todavía es necesario seguir bajando, cualquiera sea la escala de que se trate, se debe imponer exclusivamente la pena de multa ${ }^{46}$ (arts. 61 regla $5^{\text {a }}$ primera parte, 77 inc. $3^{\circ}$

\footnotetext{
${ }^{43}$ Cfr. GARRIDO MONTT, Derecho, cit. nota n’ 13, p. 319: "Si la pena asignada al delito es la de inhabilitación absoluta perpetua (escala $\mathrm{N}^{\circ} 4$ ) y debe subirse un grado, se impondrá la de reclusión menor en su grado medio, conforme a lo preceptuado por el inc. final del art. 77" (las cursivas en el original).

${ }^{44}$ En este sentido, NOVOA MONREAL, Curso, cit. nota ${ }^{\circ}$ 9, p. 359.

${ }^{45}$ Así, MATUS ACUÑA, “Artículos 74 a 78”, cit. nota n 12, pp. 406-407.

${ }^{46}$ Salvo ciertos casos especiales, como, por ejemplo, la evasión de detenidos (art. $304 \mathrm{CP}$ ) y las lesiones en riña (art. 403 inc. $2^{\circ} \mathrm{CP}$ ), figuras en las cuales la ley ordena que si se da este supuesto se aplique la última pena que contenga la respectiva escala gradual. Cfr. POLITOFF LIFSCHITZ, Sergio; MATUS ACUÑA, Jean
} 
OLIVER, Guillermo. “Algunos problemas de aplicación de reglas de determinación legal de la pena en el Código Penal chileno".

CP). Por eso, el inciso primero del artículo 60 del Código Penal señala que "la multa se considera como la pena inmediatamente inferior a la última en todas las escalas graduales". En estos casos, la cuantía de la multa ha de fijarse de acuerdo con el artículo 25 del señalado Código, atendiendo a la naturaleza de la infracción: no más de treinta unidades tributarias mensuales, tratándose de crímenes; no más de veinte de dichas unidades, tratándose de simples delitos y no más de cuatro de tales unidades, tratándose de faltas, observando los criterios del artículo 70 del mismo cuerpo legal, es decir, las circunstancias modificatorias de responsabilidad penal concurrentes y, principalmente, el caudal o facultades del condenado (art. 60 inc. $2^{\circ} \mathrm{CP}$ ).

La modificación en la naturaleza de la sanción a ser impuesta en las hipótesis de rebajas de pena que sobrepasan el tope mínimo de las escalas graduales, lo mismo que en los supuestos de aumentos de pena que superan su tope máximo, es considerada una característica negativa del sistema de determinación de pena basado en tales escalas graduales y una de las razones por las cuales se tiende a su abandono en el derecho comparado ${ }^{47}$.

Como se comprenderá, todo lo que he dicho parte de la base de que la pena a ser aumentada o disminuida se encuentre dentro de alguna de las escalas graduales del artículo 59 del Código Penal. Esta aseveración obliga a preguntarse qué sucede cuando hay que efectuar aumentos o rebajas de penas no comprendidas en dichas escalas, como ocurre, por ejemplo, con la pena de privación temporal o definitiva de la licencia de conducir ${ }^{48}$. Según algunos, si en estos casos se trata de aumentar la pena, no resulta posible asimilarla a alguna de las comprendidas en las escalas graduales para hacer la agravación, porque ello implicaría una analogía perjudicial al reo, por lo que el aumento simplemente no puede tener lugar; en cambio, si se trata de rebajarla, debe imponerse la pena de multa correspondiente, en virtud de una aplicación analógica a favor del reo, de las reglas dadas para las penas comprendidas en dichas escalas (art. 60 inc. $\left.1^{\circ} \mathrm{CP}\right)^{49}$. Según otros, en estas hipótesis el aumento de pena no puede efectuarse, pero para efectos de su rebaja debe hacerse una distinción: si su disminución obedece a la concurrencia de atenuantes, procede aplicar analógicamente aquellas reglas e imponer una

Pierre; RAMÍREZ GUZMÁN, María Cecilia, Lecciones de Derecho Penal Chileno. Parte General, $2^{\mathrm{a}}$ edición, Santiago: Editorial Jurídica de Chile, 2004, reimpresión 2008, p. 499, n. 46.

${ }^{47}$ Lo destaca, para el caso español, GALLEGO DÍAZ, Manuel, "Los procedimientos para la determinación de la pena superior e inferior en grado y la división de la pena en dos mitades. Un análisis sistemático del artículo 70 del Código Penal", en: GUZMÁN DALBORA, José Luis; SERRANO MAÍlLO, Alfonso (Eds.), Derecho penal y criminología como fundamento de la política criminal. Estudios en homenaje al profesor Alfonso Serrano Gómez, Madrid: Dykinson, 2006, pp. 727-752, p. 731. Sin embargo, en el Código Penal español, la posibilidad de imponer una sanción de naturaleza distinta a la prevista en el respectivo tipo penal no ha desaparecido del todo, ya que, con el fin de evitar la aplicación de penas privativas de libertad de muy corta duración, se obliga a sustituir la pena original, cuando por ciertas reglas que conducen a rebajar la pena en grado se arriba a una pena privativa de libertad inferior a tres meses (art. 71.2). Cfr. GARCÍA ARÁN, Mercedes, Fundamentos y aplicación de penas y medidas de seguridad en el Código Penal de 1995, Pamplona: Aranzadi, 1997, p. 84.

${ }^{48}$ La pena de multa tampoco se menciona en las escalas graduales del artículo 59 del Código Penal, pero a ella no se aplica lo que afirmo en el cuerpo de este trabajo, sino que la determinación de su monto se rige por los ya señalados criterios del artículo 70 de dicho cuerpo legal. En este mismo sentido, véanse las sentencias de la Corte de Apelaciones de La Serena, de 31 de julio de 2007, dictada en causa rol $\mathrm{N}^{\circ} 158-2007$, y de 9 de agosto de 2007, dictada en causa rol $\mathrm{N}^{\circ} 157-2007$.

${ }^{49}$ Así, MATUS ACUÑA/VAN WEEZEL, “Artículos 50 a 73”, cit. nota n 13, p. 340. 


\section{Polít. crim. Vol. 11, No 22 (Diciembre 2016), Art. 13, pp. 766-793. [http://www.politicacriminal.cl/Vol_11/n_22/Vol11N22A13.pdf]}

pena de multa; en cambio, si la rebaja se funda en que no se ha alcanzado la consumación del delito o en que no se ha intervenido en él como autor, la conducta debe quedar impune ${ }^{50}$.

En esta controversia, es la segunda opinión la correcta, por ser más respetuosa del principio de legalidad de las penas, como límite al ejercicio del ius puniendi. El aumento de la pena no puede tener lugar si la ley no establece la forma de hacerlo. La rebaja debida a circunstancias atenuantes puede obtenerse, aplicando analógicamente las reglas para disminuir las sanciones comprendidas en las escalas graduales e imponiendo una multa ${ }^{51}$. Pero la aplicación de ésta cuando la rebaja obedece a que el delito ha quedado tentado o frustrado o a que se ha intervenido en él como cómplice o encubridor, implica imponer una pena que no ha sido señalada por la ley al delito, por lo que no resulta admisible.

\section{Problemas en la regla relativa a las penas alternativas.}

Cuando un delito se sanciona por la ley con penas alternativas, el tribunal puede aplicar una de ellas para alguno(s) de los intervinientes en el hecho y otra de ellas para otro(s). Así se desprende de lo previsto en el artículo 61 regla $3^{\text {a }}$ del Código Penal, el que establece que "[s]i se designan para un delito penas alternativas, sea que se hallen comprendidas en la misma escala o en dos o más distintas, no estará obligado el tribunal a imponer a todos los responsables las de la misma naturaleza".

Resulta inexplicable que a pesar de que el Código Penal chileno no menciona explícitamente ningún criterio que deba ser utilizado por los tribunales en la elección entre penas alternativas, la doctrina, en general, tampoco se haga cargo del tema y no ofrezca pautas que puedan orientar a los jueces en esta materia ${ }^{52}$. La extrañeza aumenta si se considera que, contra lo que inicialmente podría pensarse, las hipótesis de penas alternativas en dicho Código son

\footnotetext{
${ }^{50}$ En este sentido, COUSO SALAS, “Comentario al art. 59”, cit. nota ${ }^{\circ}$ 39, pp. 557-558.

51 Aceptando la posibilidad de efectuar rebajas de penas no comprendidas expresamente en las escalas graduales del artículo 59 del Código Penal, aunque sin que ello conduzca necesariamente a la imposición de una multa, pueden verse las sentencias de la Corte de Apelaciones de San Miguel, de 6 de octubre de 2014, dictada en causa rol $\mathrm{N}^{\circ}$ 1492-2014, y de 7 de julio de 2008, dictada en causa rol $\mathrm{N}^{\circ} 724-2008$. En contra de dicha posibilidad, véanse las sentencias de la Corte de Apelaciones de Iquique, de 26 de agosto de 2014, dictada en causa rol $N^{\circ} 151-2014$, y de la Corte de Apelaciones de La Serena, de 11 de julio de 2014, dictada en causa rol $\mathrm{N}^{\circ} 204-2014$, y de 6 de agosto de 2008, dictada en causa rol $\mathrm{N}^{\circ} 178-2008$.

${ }^{52}$ NOVOA MONREAL, Curso, cit. nota ${ }^{\circ}$ 9, se limita a afirmar que "las penas alternativas se contemplan generalmente para ciertos delitos que presentan gran variedad en sus formas de ejecución o en su gravedad o en su significación social" (p. 285) y que su finalidad es "obtener una mejor individualización de la pena de cada reo, atendiendo a las particularidades propias de la intervención punible concreta que se juzga" (p. 286). A su turno, COUSO SALAS, Jaime, “Comentario al art. 61”, en: Couso Salas, Jaime; Hernández Basualto, Héctor (Dirs.), Código Penal Comentado. Parte General. Doctrina y Jurisprudencia, Santiago: Abeledo Perrot Legal Publishing Chile, 2011, pp. 561-567, p. 564, destaca la necesidad de tener en cuenta en esta materia, junto con los fines y límites de la pena, la prohibición constitucional de discriminación arbitraria. Véase también FUENTES CUBILLOS, Hernán, "El principio de proporcionalidad en derecho penal. Algunas consideraciones acerca de su concretización en el ámbito de la individualización de la pena", Ius et Praxis, Vol. 14, N 2 (2008), pp. 15-42, p. 35, n. 64, quien sugiere considerar el principio de proporcionalidad en este tema. Examina con detalle el problema, en relación con el Código Penal español, BESIO HERNÁNDEZ, Martín, Los criterios legales y judiciales de individualización de la pena, Valencia: Tirant lo Blanch, 2011, pp. 573-587.
} 
OLIVER, Guillermo. “Algunos problemas de aplicación de reglas de determinación legal de la pena en el Código Penal chileno".

muchas $^{53}$. Dejando a un lado los casos en que se entrega al tribunal la decisión de elegir entre las penas de presidio y reclusión, por carecer la distinción de importancia práctica ${ }^{54}$, más de treintaicinco artículos del Código Penal establecen penas alternativas. A veces, se trata de escoger entre una pena privativa y otra restrictiva de libertad. Así sucede, por ejemplo, en el artículo 121 (elección entre reclusión mayor, confinamiento mayor y extrañamiento mayor, en cualquiera de sus grados). En otras ocasiones, corresponde escoger entre una pena privativa de libertad y una privativa de otros derechos. Así ocurre, verbigracia, en el artículo 151 (elección entre reclusión menor y suspensión en cualquiera de sus grados). También se contemplan casos en que se debe escoger entre una pena privativa de derechos distintos de la libertad y una multa. Así acaece, por ejemplo, en el artículo 246 (elección entre suspensión del empleo en sus grados mínimo a medio y multa de seis a veinte unidades tributarias mensuales, o ambas conjuntamente). Otras veces, se trata de escoger entre dos o más penas privativas de derechos diferentes de la libertad, como sucede, verbigracia, en el artículo 249 inciso $1^{\circ}$ (elección entre inhabilitación absoluta temporal e inhabilitación absoluta perpetua para cargos u oficios públicos). También hay casos en que corresponde escoger entre una pena privativa de libertad, una restrictiva de libertad y una multa, como ocurre, por ejemplo, en el artículo 399 (elección entre relegación menor en su grado mínimo, presidio menor en su grado mínimo y multa de once a veinte unidades tributarias mensuales). No obstante, es evidente que, en la mayoría de las hipótesis de penas alternativas, de lo que se trata es de escoger entre una pena privativa de libertad y una pena de multa. Así sucede, por ejemplo, entre muchos otros casos, en el artículo 143 (elección entre reclusión menor en su grado mínimo y multa de seis a diez unidades tributarias mensuales).

Si la individualización de la pena es concebida como un proceso racional en el que cobran relevancia las ideas que se sustenten acerca de los fines de la pena, las cuales deben guiar las diferentes etapas que lo configuran, el hecho de que el legislador no señale expresamente algún criterio que deba ser considerado para escoger la sanción a imponer en las hipótesis de penas alternativas, no puede significar que exista aquí un campo para una pura discrecionalidad judicial no reglada. Debe buscarse dentro del mismo sistema penal alguna pauta orientadora de la elección de la clase de pena a aplicar.

Pues bien, del propio sistema penal puede inferirse que los criterios que deben utilizarse en esta materia son los que menciona el artículo 69 del Código Penal para determinar la cuantía exacta de las penas (privativas o restrictivas de la libertad o de otros derechos) a imponer, es decir, el número y entidad de las circunstancias atenuantes y agravantes y la mayor o menor

\footnotetext{
${ }^{53}$ Lo reconoce LABATUT GLENA, Gustavo, Derecho Penal, tomo I, 9a edición actualizada por Julio Zenteno Vargas, Santiago: Editorial Jurídica de Chile, 2000, p. 264, mencionando algunos ejemplos. También en Europa la previsión de penas alternativas constituye un recurso bastante generalizado en algunos códigos penales. Cfr. TAMARIT SUMALLA, Josep María, "Sistema de sanciones y política criminal: un estudio de Derecho comparado europeo", Revista Electrónica de Ciencia Penal y Criminología, Universidad de Granada, Vol. 9 (2007), p. 11. Pero no debe creerse que ello cuente con el beneplácito de toda la doctrina. En contra de su utilización, denunciando un atentado contra la seguridad jurídica, véase FERRAJOLI, Luigi, Derecho y razón. Teoría del garantismo penal, Trad. Andrés Ibáñez, Perfecto et alii, $4^{\mathrm{a}}$ edición, Madrid: Trotta, 2000, pp. 417-418; ÁLVAREZ GARCÍA, “La determinación”, cit. nota n 25, p. 43, n. 31.

${ }^{54}$ Cfr. CURY URZÚA, Derecho Penal, cit. nota $n^{\circ} 13$, p. 718: “en la actualidad presidio y reclusión tienden a confundirse, de manera que la distinción se ha vuelto inútil y hasta criticable".
} 
extensión del mal producido por el delito ${ }^{55}$. Estos criterios son señalados por dicho precepto para ser tenidos en cuenta en el último de los pasos del complejo proceso de individualización de la pena. Lo que afirmo es que, en los casos de penas alternativas, a falta de previsión legal expresa, tales criterios también deben ser utilizados en el primero de los pasos de aquel proceso: el de la determinación del marco penal. Aceptando como premisa que en cada una de las etapas de la individualización de la responsabilidad penal cobran importancia los fines de la pena, y que la cláusula del citado artículo 69 se muestra idónea para recoger y aplicar dichos fines, puede concluirse que, en las hipótesis de penas alternativas, ella debe utilizarse para fijar el marco penal que se considere en las etapas siguientes ${ }^{56}$.

\footnotetext{
${ }^{55}$ Atendidos los naturales límites de este trabajo, que transita por otro sendero (el de la determinación legal de la pena, no el de su individualización judicial), no puedo examinar aquí el contenido de dicho precepto legal ni, más específicamente, la procedencia de optar por una concepción amplia de la fórmula "extensión del mal producido por el delito", que incluya daños no recogidos en el tipo, o por una restringida, que considere solamente daños típicos. A favor de una concepción amplia, entre otros, véase VAN WEEZEL, Alex, "Determinación de la pena exacta: el artículo 69 del Código Penal", Ius et Praxis, N 2, año 7 (2001), pp. 401-407, p. 403. A favor de una concepción restringida, DE RIVACOBA Y RIVACOBA, Manuel, "El principio de culpabilidad en el Código Penal chileno", en: VV.AA., Actas de las Jornadas Internacionales de Derecho Penal (en celebración del centenario del Código Penal chileno), Valparaíso: Edeval, 1975, pp. 49126, pp. 122-123; RODRÍGUEZ COLLAO, Luis, "La noción de 'mal producido por el delito' en el ámbito de la criminalidad sexual", en: VAN WEEZEL, Alex (Ed.), Humanizar y renovar el derecho penal. Estudios en memoria de Enrique Cury, Santiago: Legal Publishing - Thomson Reuters, 2013, pp. 921-962, pp. 952-954. Por la misma razón, tampoco puedo analizar aquí la compatibilidad entre dicho precepto y las distintas teorías que sobre la relación entre los fines de la pena y la individualización judicial de ésta se han elaborado: teoría de la pena exacta o puntual (Punktstrafetheorie), teoría del espacio de juego (Spielraumtheorie), teoría del valor posicional o de empleo (Stellenwerttheorie), teoría de la proporcionalidad con el hecho (Tatproportionalitätlehre) y teoría de la prohibición de sobrepasar la medida de la culpabilidad (Schuldübershreitungsverbot). Sobre el contenido de dichas teorías, véase HÖRNLE, Tatjana, Determinación de la pena y culpabilidad. Notas sobre la teoría de la determinación de la pena en Alemania, Buenos Aires: Fabián J. Di Plácido Editor, 2003, passim; MAGARIÑOS, Mario, "Hacia un criterio para la determinación judicial de la pena", en: VV.AA., Determinación judicial de la pena, Buenos Aires: Editores del Puerto, 1993, pp. 71-86, pp. 73-77; DEMETRIO CRESPO, Prevención, cit. nota ${ }^{\circ}$ 3, pp. 187-214; en la doctrina nacional, brevemente, MEDINA SCHULZ, Gonzalo, "Sobre la determinación de pena y el recurso de nulidad en la Ley 20.084 sobre responsabilidad penal adolescente", Revista de Estudios de la Justicia, Universidad de Chile, Vol. 11 (2009), pp. 201-234, pp. 204-208. Por igual motivo, tampoco puedo examinar aquí la determinación del "punto de entrada" en el marco penal al considerar los criterios de la individualización judicial; mientras algunas teorías recorren el marco penal desde su mínimo, otras lo hacen desde su máximo, existiendo también posturas intermedias (teoría del caso de gravedad media, teoría del caso regular y teoría del caso regular normativo). Sobre el tema, véase ZIFFER, Patricia, "Consideraciones acerca de la problemática de la individualización de la pena", en: VV.AA., Determinación judicial de la pena, Buenos Aires: Editores del Puerto, 1993, pp. 89-110, pp. 107-109; BERTONE, Fernando Martín, Individualización judicial de la pena, Córdoba: Alveroni Ediciones, 2010, pp. 98-99; FREUND, Georg, "La determinación de las consecuencias jurídico-penales como sistema", PÉREZ SANZBERRO, Guadalupe; GARRO CARRERA, Enara (Trads.), en: ASUA BATARRITA, Adela; GARRO CARRERA, Enara (Eds.), Hechos postdelictivos y sistema de individualización de la pena, Bilbao: Servicio Editorial de la Universidad del País Vasco, 2009, pp. 26-54, pp. 34-36.

${ }^{56}$ A una conclusión similar, con matices, para el Código Penal español, con sus criterios de individualización judicial de la pena consistentes en la gravedad del hecho y las circunstancias personales del delincuente, a los que se da un alcance más general que el que fluye de la literalidad de dicho cuerpo normativo (art. 66.1 regla $6^{\text {a: }}$ "Cuando no concurran atenuantes ni agravantes...") (véase RAMOS TAPIA, María Inmaculada, "El control del arbitrio judicial en la individualización de la pena", Cuadernos de Política Criminal, Vol. 69 (1999), pp. 613-633, p. 617), llega BESIO HERNÁNDEZ, Los criterios, cit. nota n 52, p. 575. A uno de esos criterios ("la calidad del delincuente y las circunstancias personales que obren respecto de él") hizo referencia la Comisión Redactora del Código Penal chileno, al explicar la razón por la cual eliminó la exigencia,
} 
OLIVER, Guillermo. "Algunos problemas de aplicación de reglas de determinación legal de la pena en el Código Penal chileno".

Téngase presente que a pesar de que el mencionado artículo 69 hace alusión solamente a los casos en que una vez aplicadas las reglas de los artículos que le preceden se ha obtenido un grado de una pena divisible (así se desprende de la frase "[d]entro de los límites de cada grado..."), hay acuerdo en que su campo de aplicación es mucho mayor. También debe aplicarse en los casos en que, en virtud de dichas reglas, se ha determinado la mitad de un grado de una pena divisible, o bien, un marco penal compuesto por dos o más penas divisibles o indivisibles ${ }^{57}$. No debe causar extrañeza, entonces, que proponga su aplicación en la elección entre penas alternativas.

Recuérdese, además, que conforme al artículo 57 del Código Penal, si un marco penal se compone de dos o más grados, cada uno de éstos constituye una pena distinta. Pues bien, así como los criterios del citado artículo 69 deben aplicarse para fijar la cuantía exacta de la pena a imponer, entre otros casos, cuando el marco penal es uno compuesto por dos o más grados de una pena divisible (por ejemplo, presidio menor en sus grados mínimo a medio), del mismo modo deberían utilizarse para elegir penas alternativas (verbigracia, presidio menor en su grado mínimo o multa de seis a diez unidades tributarias mensuales). En el fondo, cuando en la determinación de la cuantía exacta de la pena, frente a un marco penal compuesto por dos o más grados de una pena divisible, el tribunal decide fijar una sanción precisa dentro de alguno de ellos, está realizando una verdadera elección entre dos o más penas distintas y alternativas (en nuestro ejemplo, entre el presidio menor en su grado mínimo y el presidio menor en su grado medio). Es exactamente la misma operación que debe realizar en las hipótesis de penas alternativas stricto sensu.

En todo caso, a diferencia de lo que sucede cuando se transita entre dos o más grados de una pena divisible o entre dos penas indivisibles, situación en la cual la naturaleza de la sanción no varía por la decisión judicial, la que sólo incide en la determinación de su concreta cuantía, cuando la elección se realiza entre penas alternativas stricto sensu, debe escogerse entre penas que son de distinta naturaleza, lo que obliga al tribunal a ser especialmente cauto en la aplicación de los criterios del artículo 69 del Código Penal, sobre todo cuando se trata de escoger entre una pena pecuniaria y una privativa de libertad, como ocurre generalmente ${ }^{58}$.

El mismo proceder debería seguirse en los contados casos de penas principales facultativas que nuestra legislación contempla, es decir, de penas que el tribunal está autorizado para agregar o no a su arbitrio, a otra cuya aplicación es obligatoria ${ }^{59}$, tales como los previstos en el artículo 197 del Código Penal (las multas de once a quince y de dieciséis a veinte unidades

contenida en el articulado propuesto por el comisionado Rengifo, de que, respecto de todos los responsables de un delito sancionado con penas alternativas, se adoptara una escala penal de idéntica naturaleza. Cfr. DE RIVACOBA Y RIVACOBA, Manuel (Dir.), Código Penal de la República de Chile y Actas de las Sesiones de la Comisión Redactora del Código Penal chileno, Valparaíso: Edeval, 1974, pp. 491-492.

57 Véase COUSO SALAS, Jaime, “Comentario al art. 69", en: COUSO SALAS, Jaime; HERNÁNDEZ BASUALTO, Héctor (Dirs.), Código Penal Comentado. Parte General. Doctrina y Jurisprudencia, Santiago: Abeledo Perrot Legal Publishing Chile, 2011, pp. 611-618, p. 612.

${ }^{58}$ En algunas ocasiones, los tribunales, al momento de escoger entre penas alternativas, simplemente eligen la que en el caso concreto resulte más beneficiosa para el imputado. En este sentido, véanse las sentencias de la Corte de Apelaciones de Concepción, de 22 de agosto de 2014, dictada en causa rol $N^{\circ} 444-2014$, y de la Corte de Apelaciones de Valparaíso, de 24 de diciembre de 2008, dictada en causa rol N 1306-2008.

${ }^{59}$ CURY URZÚA, Derecho Penal, cit. nota ${ }^{\circ} 13$, p. 704. 
Polít. crim. Vol. 11, No 22 (Diciembre 2016), Art. 13, pp. 766-793.

[http://www.politicacriminal.cl/Vol_11/n_22/Vol11N22A13.pdf]

tributarias mensuales pueden o no ser agregadas a las penas de presidio menor en cualquiera de sus grados y de presidio menor en su grado máximo, respectivamente). La decisión de imponer o no una pena facultativa al único culpable del delito cometido, lo mismo que la de aplicarla o no a todos o sólo a algunos de los intervinientes en el hecho, debe estar fundada en los criterios que menciona el artículo 69 de dicho cuerpo legal. Si la mayor extensión del mal producido por el delito y el número y entidad de las circunstancias agravantes concurrentes aconsejaran una reacción penal más severa, la pena facultativa debería imponerse; a la inversa, si dicha extensión fuese menor y concurrieran en el hecho circunstancias atenuantes cuyo número y entidad sugirieran una reacción menos intensa, la pena facultativa no debería aplicarse.

\section{Un concreto aspecto problemático de la regla sobre rebajas de pena en atención a formas de intervención delictiva distintas de la autoría: el caso de la complicidad en las faltas.}

La definición legal de complicidad del artículo 16 CP no limita su campo de aplicación sólo a crímenes o simples delitos. Por lo tanto, el cómplice de una falta consumada puede ser castigado. Para él se prevé una pena que no exceda de la mitad de la que corresponda a los autores (art. $498 \mathrm{CP}$ ).

Un sector de la doctrina afirma que la regla de punición del cómplice de una falta se aplica sólo cuando la pena señalada para el autor es pecuniaria, lo que sucede en la mayoría de las faltas del Libro Tercero del Código Penal, con la única excepción del hurto-falta, que prevé penas copulativas de prisión en su grado mínimo a medio y multa de una a cuatro unidades tributarias mensuales (art. 494 bis inc. $1^{\circ} \mathrm{CP}$ ). En otras palabras, dicho sector sostiene que el cómplice de un hurto-falta debe ser sancionado con una multa que no exceda de la mitad de la que corresponda al autor, sin que se le pueda imponer una pena privativa de libertad. Para aseverarlo, dicha opinión se funda en que la regla de castigo del cómplice de una falta habría sido formulada en un momento en que el Código Penal regulaba la determinación únicamente de sanciones pecuniarias, por lo que no se habría previsto para penas privativas de libertad; en que la ley no define lo que es "la mitad" de una pena compuesta de dos grados de una privativa de libertad, y en que si se impusiera al cómplice una pena privativa de libertad (que no superara la mitad de la que corresponda al autor), se produciría una desarmonía, porque al autor de un hurto-falta frustrado se le sanciona sólo con multa de una a cuatro unidades tributarias mensuales (art. 494 bis inc. $2^{\circ} \mathrm{CP}$ ), en circunstancias de que ambas situaciones (autoría de un delito frustrado y complicidad en un delito consumado) son semejantes y son tratadas de la misma manera en el artículo $52 \mathrm{CP}^{60}$.

Esta opinión no puede compartirse. La regla de punición del cómplice de una falta se aplica con total independencia de cuál sea la sanción señalada para el autor. En primer lugar, no es cierto que, en su versión original, el Código Penal haya previsto para las faltas sólo penas pecuniarias. Por el contrario, casi todas contemplaban penas privativas de libertad. Las faltas del artículo 494 se sancionaban con pena de prisión en sus grados medio a máximo o multa de

${ }^{60}$ En este sentido, COUSO SALAS, Jaime, "Comentario al art. 51", en: COUSO SALAS, Jaime; HERNÁNDEZ BASUALTO, Héctor (Dirs.), Código Penal Comentado. Parte General. Doctrina y Jurisprudencia, Santiago: Abeledo Perrot Legal Publishing Chile, 2011, pp. 544-546, pp. 545-546. 
OLIVER, Guillermo. "Algunos problemas de aplicación de reglas de determinación legal de la pena en el Código Penal chileno".

diez a cien pesos; las del artículo 495, con prisión en sus grados mínimo a medio conmutable en multa de uno a sesenta pesos, y las del artículo 496, con prisión en su grado mínimo conmutable en multa de uno a treinta pesos. Sólo la falta del artículo 497 se castigaba con pena exclusivamente pecuniaria. Por lo tanto, las penas privativas de libertad sí estaban comprendidas dentro del radio de acción de aquella regla de penalidad. Precisamente porque conforme a las reglas generales sobre rebaja de pena, el cómplice de una falta castigada con pena privativa de libertad recibiría una sanción demasiado benigna, se decidió incluir esta regla especial ${ }^{61}$.

En segundo término, para aplicar esta regla no es necesario que la ley defina lo que es la mitad de una sanción. Así como la opinión doctrinal que critico no advierte problema alguno para aplicarla a las multas, tampoco debería representar un obstáculo el hecho de que la pena del autor sea privativa de libertad. Conforme al sentido natural y obvio de las palabras, simplemente, habrá que dividir la sanción por dos y aplicar la mitad inferior. En otras palabras, se trata de realizar el mismo ejercicio que ordena el inciso tercero del artículo 67 del Código Penal para calcular el mínimum de un grado de pena divisible cuando concurre una atenuante, pero no por aplicación analógica. Por lo demás, así lo sugiere una consideración histórica. En su sesión N 114, de 2 de septiembre de 1872, la Comisión Redactora del Código Penal aprobó como texto para el actual artículo 498 el siguiente: "Los cómplices en las faltas, serán castigados con el mínimum de la pena señalada para los autores" ${ }^{\$ 2}$. No hay constancia en las actas de dicha Comisión, de las razones del cambio que experimentó el texto definitivo, pero bien podría conjeturarse que se hizo para evitar confusiones, porque la expresión mínimum es utilizada en una materia distinta y sólo cuando se está ante un grado de pena divisible. La pena del autor de una falta, en cambio, podría consistir en dos o más grados de prisión. Y si así fuera, como sucede en el hurto-falta, ningún problema habría en efectuar el mencionado cálculo. Máxime si cada uno de los grados en que puede dividirse la pena de prisión tiene la misma duración (veinte días) (art. $56 \mathrm{CP}$ ), por lo que se trata de una operación aritmética fácil de realizar. Lo que no se podría aceptar es la afirmación de que este cambio haya venido a dar cuenta de la voluntad de la ley de aplicar la regla sólo a las faltas que tengan penas pecuniarias, porque, como lo he señalado, casi todas las faltas contemplaban penas privativas de libertad.

Finalmente, la denunciada desarmonía entre la sanción del autor de un hurto-falta frustrado y la del cómplice de un hurto-falta consumado es efectiva, pero es consecuencia de la decisión del legislador de asignar a la hipótesis de frustración sólo una pena de multa. Para salvar esta indeseable situación sería necesario un cambio legal. Por lo demás, la opinión que critico también conduce a una inconsistencia valorativa, al tratar en forma distinta hechos que serían equivalentes, ya que postula que mientras al autor de hurto-falta frustrado se le sanciona con

\footnotetext{
${ }^{61}$ Véase FUENSALIDA, Alejandro, Concordancias y comentarios del Código Penal chileno, tomo III, Lima: Comercial, 1883, p. 304: “como las penas de los cómplices de faltas, en conformidad a los principios generales, vendrían a ser en algunos casos demasiado leves, la ley ha establecido una regla especial para penarlos".

${ }^{62}$ DE RIVACOBA Y RIVACOBA, Código Penal, cit. nota n 56, p. 457.
} 
Polít. crim. Vol. 11, № 22 (Diciembre 2016), Art. 13, pp. 766-793.

[http://www.politicacriminal.cl/Vol_11/n_22/Vol11N22A13.pdf]

multa de una a cuatro unidades tributarias mensuales, al cómplice de la falta consumada se le castigaría con una multa inferior, por no poder superar la mitad de aquélla ${ }^{63}$.

En consecuencia y, por ejemplo, tratándose de un hurto-falta consumado, el cómplice debería ser sancionado con prisión en su grado mínimo y multa de una a dos unidades tributarias mensuales, en tanto que, si alcanza la frustración, sólo con multa de idéntico monto. Y si se trata de la falta de perjurio (art. $212 \mathrm{CP}$ ) ${ }^{64}$, el cómplice debería ser castigado con prisión de no más de treinta días o con multa de una a dos unidades tributarias mensuales.

\section{Conclusiones}

1. El aumento de las penas compuestas por dos o más grados debe ser efectuado a partir de su grado máximo, con lo que, una vez incrementadas, se convierten en un solo grado de pena.

2. Cuando un delito se castiga con suspensión de cargo u oficio público o profesión titular, su incremento debe hacerse tanto en la escala $\mathrm{N}^{\circ} 4$, como en la $\mathrm{N}^{\circ} 5$ del artículo 59 del Código Penal, constituyendo este un supuesto especial de penas alternativas.

3. Si por aplicación de las reglas sobre aumento de grados se llega al tope máximo de las escalas $\mathrm{N}^{\circ} 4$ o $\mathrm{N}^{\circ} 5$ y aún es necesario seguir subiendo, se debe imponer la sanción superior de la respectiva escala y, además, la pena de reclusión menor en su grado medio.

4. Cuando la inhabilitación perpetua aparece como pena copulativa junto con una pena privativa de libertad, ésta absorbe a la que se derivaría de la agravación de aquélla.

5. Si se trata de penas no comprendidas en las escalas graduales del artículo 59 del Código Penal, su aumento no resulta posible. Cuando su rebaja se debe a que el delito no se ha consumado o a que no se ha intervenido como autor, el hecho debe quedar impune. Y si su disminución se funda en la concurrencia de atenuantes, procede aplicar analógicamente las reglas sobre rebaja por este motivo para penas comprendidas en dichas escalas.

6. En la elección entre penas alternativas deben utilizarse los mismos criterios que el artículo 69 del Código Penal menciona para determinar la cuantía exacta de las penas (privativas o restrictivas de la libertad o de otros derechos) a imponer, o sea, el número y entidad de las circunstancias atenuantes y agravantes y la mayor o menor extensión del mal producido por el delito.

7. Tales criterios también deben emplearse en la decisión de imponer o no una pena facultativa.

\footnotetext{
${ }^{63}$ Así lo reconoce COUSO SALAS, “Comentario al art. 51”, cit. nota ${ }^{\circ} 60$, pp. 545-546, aunque afirma que esta inconsistencia es menor que la que subyace a mi planteamiento.

${ }^{64}$ Resulta curioso que el legislador haya tipificado una falta dentro del Libro II (Crímenes y simples delitos y sus penas) del Código Penal. La constatación de cuál es su pena ("prisión en cualquiera de sus grados o multa de una a cuatro unidades tributarias mensuales") demuestra que el delito del artículo 212 del Código Penal, efectivamente, es una falta.
} 
OLIVER, Guillermo. "Algunos problemas de aplicación de reglas de determinación legal de la pena en el Código Penal chileno".

8. La regla de punición del cómplice de una falta se aplica con total independencia de cuál sea la sanción señalada para el autor.

\section{BIBLIOGRAFÍA}

ÁLVAREZ GARCÍA, Francisco Javier, "La determinación legislativa de la pena privativa de libertad", Poder Judicial, Vol. 56 (1999), pp. 35-62.

ARIAS EIBE, Manuel, Responsabilidad criminal. Circunstancias modificativas y su fundamento en el Código Penal. Una visión desde la doctrina y la jurisprudencia del Tribunal Supremo, Barcelona: Bosch, 2007.

BALMACEDA HOYOS, Gustavo, Manual de Derecho Penal. Parte General, Santiago: Librotecnia, 2014.

BERTONE, Fernando Martín, Individualización judicial de la pena, Córdoba: Alveroni Ediciones, 2010.

BESIO HERNÁNDEZ, Martín, "Aplicación del artículo 351 del Código Procesal Penal”, Política Criminal, Vol. 10, N 20 (diciembre 2015), pp. 543-596.

, Los criterios legales y judiciales de individualización de la pena, Valencia: Tirant lo Blanch, 2011.

CARRANZA TAGLE, Horacio, Introducción al concurso de delitos. Criterios sobre unidad y pluralidad delictiva, Montevideo-Buenos Aíres: B de F, 2011.

CHICHIZOLA, Mario I., La individualización de la pena, Buenos Aires: Abeledo-Perrot, 1967.

CHOCLÁN MONTALVO, José Antonio, Individualización judicial de la pena. Función de la culpabilidad y la prevención en la determinación de la sanción penal, Madrid: Colex, 1997.

CONTRERAS GUERRERO, Pablo, "Una tesis para entender la medida de la pena en los casos de reiteración de delitos de la misma especie: análisis de las reglas penológicas contenidas en el artículo 351 del Código Procesal Penal a la luz del principio de proporcionalidad constitucional", Política Criminal, Vol. 9, N 18 (diciembre 2014), pp. 614-667.

CORREA BRAVO, Agustín, "Ochenta y cuatro años de presidio", Revista Forense Chilena, Vol. 4 (1888), pp. 507-511.

CORREA SELAMÉ, Jorge, Aplicación práctica de las penas, Santiago: Editorial Jurídica Aremi, 2011.

CORTÉS ZEPEDA, José Luis, Algunos aspectos de la reiteración de delitos de la misma especie, Seminario de titulación Magíster en Derecho Penal y Ciencias Penales, Pontificia Universidad Católica de Valparaíso, Valparaíso, 2012 (texto inédito de 30 páginas).

COUSO SALAS, Jaime, "Comentario previo a los arts. 50 a 69 y 76 a 78 . El sistema de determinación de penas en el Derecho chileno" (pp. 510-524); "Comentario previo a los arts. 74 y 75 . El régimen concursal en el Derecho chileno. Tratamiento doctrinario y jurisprudencial" (pp. 625-666); "Comentario a los arts. 50, 52, 55, 56, 58, 59, 61, 69 y 76”, en: COUSO SALAS, Jaime; HERNÁNDEZ BASUALTO, Héctor (Dirs.), 
Polít. crim. Vol. 11, № 22 (Diciembre 2016), Art. 13, pp. 766-793.

[http://www.politicacriminal.cl/Vol_11/n_22/Vol11N22A13.pdf]

Código Penal Comentado. Parte General. Doctrina y Jurisprudencia, Santiago: Abeledo Perrot Legal Publishing Chile, 2011.

CUERDA RIEZU, Antonio, Concurso de delitos y determinación de la pena, Madrid: Tecnos, 1991.

CURY URZÚA, Enrique, Derecho Penal. Parte General, 10ª edición, Santiago: Ediciones Universidad Católica de Chile, 2011.

DE RIVACOBA Y RIVACOBA, Manuel, Función y aplicación de la pena, Buenos Aires: Depalma, 1993.

"El principio de culpabilidad en el Código Penal chileno", en: VV.AA., Actas de las Jornadas Internacionales de Derecho Penal (en celebración del centenario del Código Penal chileno), Valparaíso: Edeval, 1975, pp. 49-126.

DE RIVACOBA Y RIVACOBA, Manuel (Dir.), Código Penal de la República de Chile y Actas de las Sesiones de la Comisión Redactora del Código Penal chileno, Valparaíso: Edeval, 1974.

DEMETRIO CRESPO, Eduardo, Prevención general e individualización judicial de la pena, Salamanca: Ediciones Universidad de Salamanca, 1999.

ETCHEBERRY, Alfredo, Derecho Penal. Parte General, tomos I y II, $3^{\text {a }}$ edición, Santiago: Editorial Jurídica de Chile, 1998.

FERRAJOLI, Luigi, Derecho y razón. Teoría del garantismo penal, Trad. Andrés Ibáñez, Perfecto et alii, $4^{\text {a }}$ edición, Madrid: Trotta, 2000.

FONTECILLA RIQUELME, Rafael, Concursos de delincuentes, de delitos y de leyes penales y sus principales problemas jurídicos, Santiago: Editorial Jurídica de Chile, 1956.

FUENSALIDA, Alejandro, Concordancias y comentarios del Código Penal chileno, tomo III, Lima: Comercial, 1883.

FUENTES CUBILLOS, Hernán, "El principio de proporcionalidad en derecho penal. Algunas consideraciones acerca de su concretización en el ámbito de la individualización de la pena", Ius et Praxis, Vol. 14, N² 2 (2008), pp. 15-42.

GALLEGO DÍAZ, Manuel, "Los procedimientos para la determinación de la pena superior e inferior en grado y la división de la pena en dos mitades. Un análisis sistemático del artículo 70 del Código Penal", en: GUZMÁN DALBORA, José Luis; SERRANO MAÍlLLO, Alfonso (Eds.), Derecho penal y criminología como fundamento de la política criminal. Estudios en homenaje al profesor Alfonso Serrano Gómez, Madrid: Dykinson, 2006, pp. 727-752.

GALLEGO DÍAZ, Manuel, "El sistema general de reglas para la aplicación de las penas del Código Penal de 1995 y las últimas reformas", en: OCTAVIO DE TOLEDO Y UBIETO, Emilio; GURDIEL SIERRA, Manuel; CORTÉS BECHIARELLI, Emilio (Coords.), Estudios penales en recuerdo del profesor Ruiz Antón, Valencia: Tirant lo Blanch, 2004, pp. 321-353.

GARCÍA ARÁN, Mercedes, Fundamentos y aplicación de penas y medidas de seguridad en el Código Penal de 1995, Pamplona: Aranzadi, 1997.

Los criterios de determinación de la pena en el Derecho español, Barcelona: Ediciones de la Universidad de Barcelona, 1982.

GARRIDO MONTT, Mario, Derecho Penal. Parte General, tomo I, $2^{\text {a }}$ edición, Santiago: Editorial Jurídica de Chile, 2005. 
OLIVER, Guillermo. “Algunos problemas de aplicación de reglas de determinación legal de la pena en el Código Penal chileno".

GÓMEZ QUITRAL, Graciela, “Algunas consideraciones sobre la determinación de la pena y el arbitrio judicial”, Cuadernos Judiciales, Instituto de Estudios Judiciales, Vol. 6 (mayo 2002), pp. 60-72.

GONZÁLEZ CUSSAC, José Luis, Teoría general de las circunstancias modificativas de responsabilidad criminal, Valencia: Universidad de Valencia, 1988.

GUZMÁN DALBORA, José Luis, La pena y la extinción de la responsabilidad penal, Santiago: Legal Publishing, 2008.

HERNÁNDEZ BASUALTO, Héctor, "Comentario al art. 14", en: COUSO SALAS, Jaime; HERNÁNDEZ BASUALTO, Héctor (Dirs.), Código Penal Comentado. Parte General. Doctrina y Jurisprudencia, Santiago: Abeledo Perrot Legal Publishing Chile, 2011, pp. 365-382.

HÖRNLE, Tatjana, Determinación de la pena y culpabilidad. Notas sobre la teoría de la determinación de la pena en Alemania, Buenos Aires: Fabián J. Di Plácido Editor, 2003.

HURTADO E., Paula; VARGAS O., Gonzalo, "Aplicación de penas en Chile”, Boletín Jurídico del Ministerio de Justicia, Vol. 2, N 4-5 (noviembre 2003), pp. 59-71.

LABATUT GLENA, Gustavo, Derecho Penal, tomo I, 9a edición actualizada por Julio Zenteno Vargas, Santiago: Editorial Jurídica de Chile, 2000.

LLORCA ORTEGA, José, Manual de determinación de la pena, $6^{\mathrm{a}}$ edición, Valencia: Tirant lo Blanch, 2005.

MAGARIÑOS, Mario, "Hacia un criterio para la determinación judicial de la pena", en: VV.AA., Determinación judicial de la pena, Buenos Aires: Editores del Puerto, 1993, pp. 71-86.

MALDONADO FUENTES, Francisco, "Reiteración y concurso de delitos. Consideraciones sobre el artículo 351 del Código Procesal Penal a partir de la teoría general del concurso de delitos en el Derecho chileno", en: CÁRDENAS ARAVENA, Claudia; FERDMAN NIEDMANN, Jorge (Coords.), El Derecho penal como teoría y como práctica. Libro en homenaje a Alfredo Etcheberry Orthusteguy, Santiago: Thomson Reuters - Legal Publishing, 2016, pp. 549-607.

MAÑALICH RAFFO, Juan Pablo, "La reiteración de hechos punibles como concurso real. Sobre la conmensurabilidad típica de los hechos concurrentes como criterio de determinación de la pena", Política Criminal, Vol. 10, N$^{\circ} 20$ (diciembre 2015), pp. 498-527.

, “Discrecionalidad judicial en la determinación de la pena en caso de concurrencia de circunstancias atenuantes de la responsabilidad penal?", Informes en Derecho. Doctrina Procesal Penal 2009, N 7 (octubre 2010), pp. 41-67.

, "Determinación y ejecución de la pena", Revista de Derecho, Universidad Adolfo Ibáñez, Vol. 2 (2005), pp. 483-529.

"El concurso de delitos: bases para su reconstrucción en el Derecho penal de Puerto Rico", Revista Jurídica de la Universidad de Puerto Rico, Vol. 74 (2005), pp. 1021-1211.

MATUS ACUÑA, Jean Pierre, “Artículos 74 a 78”, en: POLITOFF LIFSCHITZ, Sergio; ORTIZ QUIROGA, Luis (Dirs.); MATUS ACUÑA, Jean Pierre (Coord.), Texto y comentario del Código Penal chileno, tomo I, Santiago: Editorial Jurídica de Chile, 2002, pp. 383-407. 
Polít. crim. Vol. 11, № 22 (Diciembre 2016), Art. 13, pp. 766-793.

[http://www.politicacriminal.cl/Vol_11/n_22/Vol11N22A13.pdf]

MATUS ACUÑA, Jean Pierre; RAMÍREZ GUZMÁN, María Cecilia, Lecciones de Derecho Penal Chileno. Parte Especial, $3^{\mathrm{a}}$ edición, Santiago: Thomson Reuters Legal Publishing, 2014.

MATUS ACUÑA, Jean Pierre; VAN WEEZEL, Alex, “Artículos 50 a 73”, en: POLITOFF LIFSCHITZ, Sergio; ORTIZ QUIROGA, Luis (Dirs.); MATUS ACUÑA, Jean Pierre (Coord.), Texto y comentario del Código Penal chileno, tomo I, Santiago: Editorial Jurídica de Chile, 2002, pp. 323-382.

MEDINA SCHULZ, Gonzalo, "Sobre la determinación de pena y el recurso de nulidad en la Ley 20.084 sobre responsabilidad penal adolescente", Revista de Estudios de la Justicia, Universidad de Chile, Vol. 11 (2009), pp. 201-234.

NÁQUIRA RIVEROS, Jaime et alii, "Principios y penas en el Derecho penal chileno", Revista Electrónica de Ciencia Penal y Criminología, Universidad de Granada, Vol. 10 (2008).

NOVOA MONREAL, Eduardo, Curso de Derecho Penal Chileno. Parte General, tomo II, $3^{\mathrm{a}}$ edición, Santiago: Editorial Jurídica de Chile, 2005.

OBREGÓN GARCÍA, Antonio, "Determinación de la pena”, en: MOLINA BLÁZQUEZ, María Concepción (Coord.), La aplicación de las consecuencias jurídicas del delito, Barcelona: Bosch, 2005, pp. 75-112.

OLIVER CALDERÓN, Guillermo, "La exasperación de la pena en el concurso material de delitos: la reiteración de delitos de la misma especie", Revista de Derecho Universidad Austral de Chile, Vol. XXVI, N² (diciembre 2013), pp. 167-188.

ORTIZ QUIROGA, Luis; ARÉVALO CUNICH, Javier, Las consecuencias jurídicas del delito, Santiago: Editorial Jurídica de Chile, 2013.

PICA URRUTIA, René, Reglas para la aplicación de las penas, $4^{\text {a }}$ edición, Santiago: Editorial Jurídica de Chile, 1992.

POLITOFF LIFSCHITZ, Sergio, Derecho Penal, tomo I, Santiago: Editorial Jurídica Conosur, 1997.

POLITOFF LIFSCHITZ, Sergio; MATUS ACUÑA, Jean Pierre; RAMÍREZ GUZMÁN, María Cecilia, Lecciones de Derecho Penal Chileno. Parte General, $2^{\mathrm{a}}$ edición, Santiago: Editorial Jurídica de Chile, 2004, reimpresión 2008.

POSADA MAYA, Ricardo; HERNÁNDEZ BELTRÁN, Harold M., El sistema de individualización de la pena en el Derecho penal colombiano, Medellín: Universidad Pontificia Bolivariana - Biblioteca Jurídica Diké, 2001.

RAMOS TAPIA, María Inmaculada, "El control del arbitrio judicial en la individualización de la pena", Cuadernos de Política Criminal, Vol. 69 (1999), pp. 613-633.

REYES ALVARADO, Yesid, El concurso de delitos, Bogotá: Reyes Echandía Abogados, 1990.

RODRÍGUEZ COLLAO, Luis, “La noción de 'mal producido por el delito' en el ámbito de la criminalidad sexual”, en: VAN WEEZEL, Alex (Ed.), Humanizar y renovar el derecho penal. Estudios en memoria de Enrique Cury, Santiago: Legal Publishing Thomson Reuters, 2013, pp. 921-962.

"Naturaleza y fundamento de las circunstancias modificatorias de la responsabilidad criminal", Revista de Derecho Pontificia Universidad Católica de Valparaíso, Vol. 36, № 1 (2011), pp. 397-428.

SALEILLES, Raymond, La individualización de la pena, $2^{\mathrm{a}}$ edición, Trad.: De Hinojosa, Juan, Bogotá: Editorial Leyer, 2005. 
OLIVER, Guillermo. “Algunos problemas de aplicación de reglas de determinación legal de la pena en el Código Penal chileno".

SÁNCHEZ GARCÍA, María Isabel, "El sistema de penas", Revista Jurídica Española La Ley, Vol. 2 (1996), pp. 1499-1516.

SANZ MORÁN, Ángel José, El concurso de delitos. Aspectos de política legislativa, Valladolid: Universidad de Valladolid, 1986.

SOLARI PERALTA, Tito; RODRÍGUEZ COLLAO, Luis, "Determinación de la pena en los casos de reiteración de delitos (ámbito de aplicación del artículo 509 del Código de Procedimiento Penal)", Revista de Derecho, Universidad Católica de Valparaíso, Vol. 3 (1979).

SUÁREZ LÓPEZ, José María, El concurso real de delitos, Madrid: Edersa, 2001.

TAMARIT SUMALLA, Josep María, "Sistema de sanciones y política criminal: un estudio de Derecho comparado europeo", Revista Electrónica de Ciencia Penal y Criminología, Universidad de Granada, Vol. 9 (2007).

VAN WEEZEL, Alex, "Determinación de la pena exacta: el artículo 69 del Código Penal", Ius et Praxis, $\mathrm{N}^{\circ}$ 2, año 7 (2001), pp. 401-407.

, "Compensación racional de atenuantes y agravantes en la medición judicial de la pena", Revista Chilena de Derecho, Vol. 24, N 3 (1997), pp. 459-502.

VARGAS PINTO, Tatiana, Manual práctico de aplicación de la pena, Santiago: Thomson Reuters Legal Publishing, 2014.

VIVANCO SEPÚLVEDA, Jaime, "Manera y oportunidad de aumentar la pena en caso de reiteración de delitos de la misma especie. Comentario a sentencia de Corte Suprema de 9 de junio de 1970", Revista de Ciencias Penales, Vol. 29, № 3 (septiembre diciembre 1970).

ZIFFER, Patricia, "Consideraciones acerca de la problemática de la individualización de la pena”, en: VV.AA., Determinación judicial de la pena, Buenos Aires: Editores del Puerto, 1993, pp. 89-110.

ZUGALDÍA ESPINAR, José Miguel, Fundamentos de Derecho Penal, $3^{\text {a }}$ edición, Valencia: Tirant lo Blanch, 1993.

, "La individualización de la pena en el borrador de parte general del Anteproyecto de Código Penal de 1990”, Cuadernos de Política Criminal, Vol. 44 (1991), pp. 459467. 